UNIVERSIDADE DE SÃO PAULO

FACULDADE DE ECONOMIA, ADMINISTRAÇÃO E CONTABILIDADE

DEPARTAMENTO DE ECONOMIA

\title{
Estimando o Preço Implícito de Amenidades Urbanas: Evidências para o Município de São Paulo
}

\author{
Bruno Martins Hermann \\ Orientador: Prof. Dr. Eduardo Amaral Haddad
}

São Paulo 
Reitor da Universidade de São Paulo

Professor Dr. Adolpho José Melfi

Diretora da Faculdade de Economia, Administração e Contabilidade Professora Dra. Maria Tereza Leme Fleury

Chefe do Departamento de Economia

Professora Dra. Elizabeth Maria Mercier Querido Farina 


\section{Estimando o Preço Implícito de Amenidades Urbanas: Evidências para o Município de São Paulo}

Candidato: Bruno Martins Hermann

Orientador: Prof. Dr. Eduardo Amaral Haddad

Versão para Defesa de Dissertação apresentada ao Departamento de Economia da Faculdade de Economia Administração e Contabilidade da Universidade de São Paulo para a obtenção do Título de Mestre em Economia - área de especialização em Teoria Econômica 


\section{Agradecimentos}

Em primeiro lugar gostaria de agradecer ao Prof. Eduardo Haddad por abrir-me as portas à literatura de economia regional e urbana. Por muito tempo venho buscando um arcabouço teórico e metodológico que me satisfaça na compreensão dos fenômenos espaciais - hoje, posso dizer que me sinto realizado por conhecer as diversas pesquisas de ponta no setor. Gostaria ainda de agradecê-lo por sua competência e serenidade, que foram fundamentais para a consecução deste trabalho.

Gostaria de agradecer também ao Prof. Ciro Biderman pela receptividade em discussões e para o esclarecimento de dúvidas; ao Prof. Geoffrey Hewings pela atenção dispensada ao meu trabalho; aos Profs. Carlos Roberto Azzoni e Roberto Guena de Oliveira pelas diversas sugestões propostas ainda na qualificação; aos colegas do mestrado Luiz Cherman, Pricila Maziero, Anderson Schneider, Luiz Barcellos, Gustavo Soares, Daulins Emílio, Eduardo Rodrigues, Márcio Diniz, Fernado Postali e Alan Dario, que muitas vezes foram solicitados para debaterem assuntos do meu interesse; aos Profs. André Portela, Reynaldo Fernandes, Fábio Kanczuk e Naércio Menezes, pelas críticas e sugestões em seminário. Muitas vezes percebi que minha narrativa durante a elaboração do texto dirigia-se ao público dos "Seminários de Sexta" no Departamento de Economia da USP.

Sou grato às Profas. Regina Meyer e Marta Grostein, por cederem informações e a infra-estrutura do Laboratório de Urbanismo da Metrópole para o meu trabalho e a todo o pessoal do Lume, Luciana Travassos, Mila e Paula Santoro, Lúcia Silva e Souza e Taís Tsukumo, por me ajudarem na pesquisa. Vocês realmente conseguiram ensinar geoprocessamento a um geógrafo.

Agradeço também aos colegas Edson Domingues e Eduardo Almeida, do Núcleo de Estudos Regionais e Urbanos da USP (Nereus), pela amizade e a ajuda na realização dos testes de econometria espacial; e ao colega Fernando Cotelo pela colaboração na revisão final do texto. 
Gostaria, ainda, de agradecer à minha família - minha mãe Leila, meu pai João André, Beth, Luci e meus avós, Gilda e Arthur - pelo apoio incessante e aos amigos - Dana, Bernardo, Isabela e Jéssica - pelo apoio e conforto emocional.

Por fim, devo ainda mencionar o apoio de instituições, sem o qual este trabalho não teria sido possível. Meus agradecimentos ao CNPq, pela bolsa referente ao curso de mestrado, e à Fipe, pelo suporte financeiro em diversas atividades extracurriculares. 


\section{Sumário}

$\begin{array}{ll}\text { Lista de Tabelas } & 7\end{array}$

$\begin{array}{ll}\text { Lista de Gráficos } & 7\end{array}$

$\begin{array}{lr}\text { Lista de Mapas } & 8\end{array}$

$\begin{array}{lr}\text { Resumo } & 9\end{array}$

$\begin{array}{ll}\text { 1. Introdução } & 11\end{array}$

2. Fundamentação Teórica $\quad 14$

2.1 Problemas na Estimação de Amenidades 14

2.2 O Modelo de Preços Hedônicos 15

3. Método de Estimação 23

3.1 Problemas na Estimação de Preços Hedônicos 23

3.2 Especificação e Teste 26

4. Acessibilidade $\quad 30$

4.1 Configuração Urbana Monocêntrica 30

4.2 Configuração Urbana Duocêntrica 36

5. O Banco de Dados 39

5.1 Amostra de Domicílios 39

5.2 Seleção de Variáveis Ambientais 42

6. Resultados 51

7. Considerações Finais

$\begin{array}{lr}\text { 8. Bibliografia } & 63\end{array}$

$\begin{array}{lr}\text { 9. Apêndice } & 65\end{array}$ 


\section{Lista de Tabelas}

Tabela 1 Emprego Total por Distrito - São Paulo 33

Tabela 2 Emprego no Setor de Serviços por Distrito - São Paulo 36

Tabela $3 \quad$ Variável Independente e Variáveis de Controle 41

Tabela $4 \quad$ Variáveis Ambientais 49

Tabela $5 \quad$ Regressão Linear sobre Variáveis Ambientais 51

Tabela $6 \quad$ Matriz de Cargas Fatoriais Rotacionadas 55

Tabela $7 \quad$ Regressão Linear sobre Fatores 56

Tabela $8 \quad$ Análise de Dependência Espacial 57

Tabela $9 \quad$ Aluguel para Cinco Domicílios Similares 60

Tabela A1 Regressão Linear sobre Variáveis de Controle 65

Tabela A2 Correlograma-Renda x Variáveis Ambientais 65

Tabela A3 Variância Explicada pelos Fatores 66

Tabela A4 Partículas Inaláveis por Estação Medidora-São Paulo 66

Tabela A5 Variáveis Ambientais por Distrito - São Paulo 67

Tabela A6 Agregação das Zonas Urbanas 69

\section{Lista de Gráficos}

$\begin{array}{lll}\text { Gráfico } 1 \quad \text { Escolha do Consumidor } & 17\end{array}$

$\begin{array}{ll}\text { Gráfico } 2 \text { Decisão do Produtor } & 18\end{array}$

Gráfico 3 Equilíbrio de Mercado 19

Gráfico $4 \quad$ Função de Preços Hedônicos 20

Gráfico $5 \quad$ Modelo Monocêntrico 31

Gráfico $6 \quad$ Modelo Duocêntrico 37 


\section{Lista de Mapas}

Mapa $1 \quad$ Número de Empregos Totais e Importação/Exportação

de Empregos por Distrito - São Paulo 32

Mapa 2 Número de Empregos no Setor de Serviços e

Importação/Exportação de Empregos por Distrito - São Paulo 35

Mapa 3 Amostra de Domicílios - São Paulo 40

Mapa $4 \quad$ Interpolação de Resíduos da Regressão 1 - São Paulo 43

Mapa $5 \quad$ Interpolação de Resíduos da Regressão 2 - São Paulo 45

Mapa $6 \quad$ Interpolação de Resíduos da Regressão 3 - São Paulo 46

Mapa $7 \quad$ Interpolação de Resíduos da Regressão 4 - São Paulo 47

Mapa $8 \quad$ Localização de Cinco Domicílios Similares 59

$\begin{array}{lll}\text { Mapa A1 Sistema Ferroviário - São Paulo } & 70\end{array}$

Mapa A2 Estações Medidoras de Poluição - São Paulo 71

Mapa A3 Características Distritais - Coeficiente Arbóreo - São Paulo 72

Mapa A4 Características Distritais - Taxa de Construção Comercial e

Industrial - São Paulo 73

Mapa A5 Características Distritais - Índice de Criminalidade e

População Favelada - São Paulo 74 


\section{Resumo}

Neste trabalho, utilizamos uma equação hedônica para estimar o preço implícito de amenidades urbanas a partir de dados do mercado de imóveis no Município de São Paulo. São testadas duas especificações: uma com as variáveis explicativas originais e outra com a construção de fatores para correção de multicolinearidade. Além de considerar a configuração monocêntrica tradicional, propomos a inclusão de um vetor de acessibilidade para o caso de uma cidade duocêntrica. A investigação sobre as variáveis ambientais relevantes é fundamentada na interpolação espacial dos resíduos. Concluímos que a proximidade das estações de trem, a presença de áreas verdes e o zoneamento estritamente residencial valorizam o imóvel para fins residenciais, enquanto a criminalidade reduz o seu valor. 


\begin{abstract}
In this article, we use a hedonic equation to estimate the implicit prices of urban amenities based on housing market data for the city of São Paulo. We test two different specifications, one with the original independent variables, and another with factors to correct for multicollinearity. In addition to the traditional monocentric model, we include an accessibility vector for a duocentric city. A criterion to select the appropriate environmental variables based on residual spatial interpolation is introduced. We conclude that proximity to train stations, green areas and strict residential zones raise rents, while criminality reduces them.
\end{abstract}




\section{Introdução}

Tradicionalmente, na literatura econômica, o bem-estar da sociedade está associado à sua capacidade de gerar os bens necessários e desejados ao consumo dos indivíduos. Quanto maior o consumo de bens, satisfeitas as hipóteses de racionalidade, maior o nível de bem estar atingido. A noção de consumo está relacionada, de maneira geral, à transformação de bens materiais. Entretanto, quando introduzimos a dimensão espacial, observamos que uma parcela da satisfação dos indivíduos depende das características específicas de cada localização. Os agentes econômicos possuem um endereço, residem e trabalham majoritariamente em cidades. Portanto, observamos que a presença ou a ausência de amenidades urbanas interfere diretamente no bem-estar deles. Neste caso, podemos extrapolar a noção de consumo, incorporando um conjunto específico de amenidades urbanas à cesta dos agentes. Assim, entendemos que as escolhas dos indivíduos dependem, além da preferência por um conjunto de bens materiais, de uma parcela de bens não-materiais que refletem a qualidade de vida dos centros urbanos.

O estudo de valoração dessas amenidades revela-se importante para a compreensão do impacto do meio urbano sobre os indivíduos. Qualquer alteração no espaço físico das cidades pode ter conseqüências sobre o preço das moradias e sobre o bem-estar dos agentes. A escolha residencial das famílias e a migração intra-urbana dependem da localização de amenidades. Assim, além das variáveis usuais de análise, como produção, emprego, entre outras, a presença de amenidades urbanas motiva estudos para a compreensão da satisfação dos indivíduos. Políticas públicas ou ações privadas com potencial impacto sobre o meio urbano seriam mais bem avaliadas sob essa perspectiva.

Entendemos por amenidades urbanas um conjunto de características específicas de uma localidade com contribuição positiva ou negativa para a satisfação dos indivíduos. ${ }^{1}$ As amenidades não estão restritas a características naturais, como áreas verdes, praias, clima, etc. Também estão incluídos na definição os bens (ou males) gerados pelo próprio homem, tais como trânsito, poluição, oferta de entretenimento, segurança, etc.

\footnotetext{
${ }^{1}$ Ver Bartik et al. (1987).
} 
A valoração de amenidades urbanas não é algo trivial. Enquanto na maioria dos mercados podemos observar as quantidades transacionadas e os preços dos produtos, no caso das amenidades isto não acontece. ${ }^{2}$ Embora possamos supor que exista uma oferta, uma demanda e um preço de equilíbrio para as diferentes amenidades, não podemos coletar esses dados diretamente do mercado. Não existe explicitamente um mercado de compra e venda de trânsito, ou um mercado de compra e venda de poluição. Dadas essas dificuldades, devemos, pois, recorrer a algum modelo alternativo que seja capaz de revelar essas informações.

O modelo mais utilizado na literatura para esse fim é o de preços hedônicos. Este considera um bem heterogêneo como um pacote fechado de atributos e estima o preço marginal de cada atributo a partir da análise do valor observado do bem heterogêneo e de suas respectivas quantidades de atributos. ${ }^{3}$ Podemos considerar um imóvel como um bem heterogêneo, com valor observado, composto de um pacote de características, no qual se incluem as amenidades urbanas de sua localidade. Supomos que as famílias, quando fazem escolhas residenciais, não estão preocupadas apenas com o que existe da janela para dentro do imóvel, mas também com o que existe da janela para fora. Ou seja, a vizinhança interfere na qualidade do imóvel e, portanto, afeta seu preço de locação. Analisando o mercado privado de aluguéis, podemos inferir sobre o preço das amenidades.

O modelo de preços hedônicos para habitação vem sendo largamente utilizado para medir o valor marginal das características intrínsecas, ou estruturais do imóvel, e também para estimar variáveis sócio-ambientais correlacionadas. Dentre os estudos recentes podemos destacar os de Bowes e Ihlanfeldt (2001), que avaliam o impacto das estações de trem sobre o valor dos imóveis para Atlanta, Estados Unidos; de Espey e Lopez (2000), que pesquisam o efeito do barulho dos aeroportos em Reno-Sparks, Estados Unidos; de Benson et al. (1998), que avaliam o impacto da vista sobre o preço dos imóveis em Bellingham, Canadá; de Macedo (1998), que estimam o preço de variáveis estruturais em Belo Horizonte, Brasil; e de Andersson (1997), que analisam a qualidade dos condomínios em Singapura, Malásia. Para a cidade de São Paulo, especificamente, há pelo menos dois estudos que aplicam o modelo hedônico: Biderman

\footnotetext{
${ }^{2}$ Ver Sheppard (1999).

${ }^{3}$ Ver Rosen (1974).
} 
(2001) avalia a demanda por imóveis novos e Oliveira (1997) estima o preço negativo da poluição do ar.

O objetivo deste trabalho é procurar, na medida do possível, esgotar todo o efeito vizinhança sobre o valor dos aluguéis. A dissertação está desenvolvida da seguinte maneira: na seção 2, fazemos um resumo do modelo de preços hedônicos e sua aplicação para o mercado de aluguéis; na seção 3, apresentamos um conjunto de problemas recorrentes na estimação de preços hedônicos e explicitamos o método escolhido; na seção 4, fazemos algumas considerações sobre a configuração urbana assumida para a cidade de São Paulo; na seção 5, apresentamos os dados utilizados na pesquisa e desenvolvemos um critério para seleção de variáveis ambientais; na seção 6, apresentamos os resultados obtidos; e, na seção 7, tecemos algumas conclusões sobre o trabalho. 


\section{Fundamentação Teórica}

\subsection{Problemas na Estimação do Preço de Amenidades}

A maioria dos modelos econômicos trata de interações entre os agentes que se dão via mercado. Produtores e consumidores podem tomar suas decisões otimizadoras, baseados em informações sobre preços e suas próprias capacidades de produção e consumo. Entretanto, para estudarmos o impacto de amenidades urbanas sobre a moradia, precisamos extrapolar essa hipótese. Consumidores não fazem escolhas diretas sobre a quantidade de poluição ou de segurança que desejam adquirir. Um novo edifício erguido em uma quadra horizontal toma a privacidade dos antigos moradores, que, por sua vez, não pagaram ou obtiveram nada por isso. Os agentes econômicos importam-se com essas características locais, que, contudo, não são vendidas no mercado.

Quando estudamos as externalidades geradas pelas amenidades urbanas, enfrentamos a limitação de desconhecer o seu verdadeiro valor. Ou seja, não existe propriamente um mercado para esse tipo de "produto", portanto, não podemos observar o seu preço. Contudo, podemos assumir que existe implicitamente uma oferta e uma demanda por essas características e, dessa forma, tentar inferir seus respectivos preços de equilíbrio. Este é o roteiro traçado pelo modelo de preços hedônicos. O preço marginal dos atributos é estimado, fazendo regredir o preço do bem heterogêneo sobre as quantidades de características associadas.

Entretanto, a implementação do modelo para o mercado de imóveis esbarra em mais um problema. Sabemos exatamente quais são as amenidades e as magnitudes consumidas pelos agentes? Provavelmente não. Para Sheppard (1999) a pesquisa sobre preços hedônicos assemelha-se a uma situação na qual um pesquisador, impossibilitado de entrar num supermercado, deve inferir sobre o preço dos produtos, apenas com base na informação do valor total da conta de cada família, de suas respectivas características, como gostos e renda, e em uma visão turva das quantidades de produtos que circulam dentro dos carrinhos. 
Isso é essencialmente o que acontece quando empreendemos uma análise hedônica para o mercado de imóveis (ou aluguéis). O preço do bem final geralmente é conhecido com clareza. Entretanto, informações sobre as quantidades de características consumidas são bastante imprecisas. Embora possamos aceitar que as características observadas da janela para fora dos imóveis afetam seu preço de locação, não sabemos quais dessas amenidades estão sendo consumidas e em que quantidades exatas. Como veremos, a solução freqüentemente utilizada para esse problema é assumir ad hoc o pacote de atributos relevantes e designar suas quantidades de acordo com a unidade territorial escolhida.

Como observamos, a análise de preços hedônicos é caracterizada pela estimação de uma "função preço", com o preço do aluguel de um lado e o pacote de características de outro. A apresentação isolada dessa função mascara o conteúdo microeconômico do modelo. Assim, parece-nos conveniente explicitar o mecanismo gerador das observações e, com isso, clarificar o significado dos preços hedônicos a serem estimados. Para tal, vamos considerar a abordagem de Rosen (1974) para o caso de mercados competitivos.

\subsection{O Modelo de Preços Hedônicos}

O modelo descreve um equilíbrio competitivo em um plano de dimensão $n$, no qual compradores e vendedores se alocam. O bem heterogêneo é composto de $n$ características e cada consumidor adquire apenas uma unidade do bem. A função utilidade dos consumidores é descrita como $U\left(x, z_{1}, z_{2}, \ldots, z_{n}\right.$; $\left.\alpha\right)$, onde $z_{i}$ é o atributo $i$ do bem composto, $x$ representa todos os outros bens consumidos e $\alpha$ é um parâmetro de preferências do consumidor. Definindo o preço de $x$ como numerário, obtemos a restrição orçamentária do consumidor: $y=x+p(z)$. A maximização da utilidade depende da escolha de $x$ e $\left(z_{1}, z_{2}, \ldots, z_{n}\right)$ que satisfaça a restrição orçamentária. A condição de primeira ordem é dada pela seguinte expressão:

$$
\frac{\partial p(z)}{\partial z_{i}} \equiv p_{z i}=\frac{U_{z i}}{U_{x}}
$$


onde $p_{z i}$ é identificado como o preço hedônico do atributo $i$ e $p(z)$ é a função de preços hedônicos.

Para completar o contexto espacial do modelo, definimos $\theta\left(z_{1}, z_{2}, \ldots, z_{n} ; u, y, \alpha\right)$ como a "função dispêndio" do consumidor: ${ }^{4}$

$U\left(y-\theta, z_{1}, z_{2}, \ldots, z_{n} ; \alpha\right)=u$

A "função dispêndio" indica o quanto o consumidor está disposto a pagar por pacotes alternativos de atributos $\left(z_{1}, z_{2}, \ldots, z_{n}\right)$, dado um nível de utilidade $u$. Derivando (2), obtemos:

$\theta_{z i}=\frac{U_{z i}}{U_{x}}$

onde $\theta_{z i}$ é a taxa marginal de substituição entre o atributo $z_{i}$ e dinheiro, revelando o preço de reserva do consumidor por uma unidade adicional da característica $i$.

Como $\theta\left(z_{1}, z_{2}, \ldots, z_{n} ; u, y, \alpha\right)$ revela o quanto o consumidor está disposto a pagar pelo bem composto $z$ e $p(z)$ mostra o preço mínimo que ele deve pagar no mercado, a utilidade é maximizada quando:

$\theta\left(z_{1}, z_{2}, \ldots, z_{n} ; u, y, \alpha\right)=p(z)$

e

$\theta_{z i}=p_{z i}$

Assim, uma família de curvas de indiferença é definida por $\theta\left(z_{1}, z_{2}, \ldots, z_{n} ; u, Y\right)$ para cada consumidor, e a escolha ótima ocorre quando $\theta\left(z_{1}, z_{2}, \ldots, z_{n} ; u, Y\right)$ e $p(z)$ são tangentes, como mostra o Gráfico 1.

\footnotetext{
4 "Bid function".
} 
Gráfico 1: Escolha do Consumidor

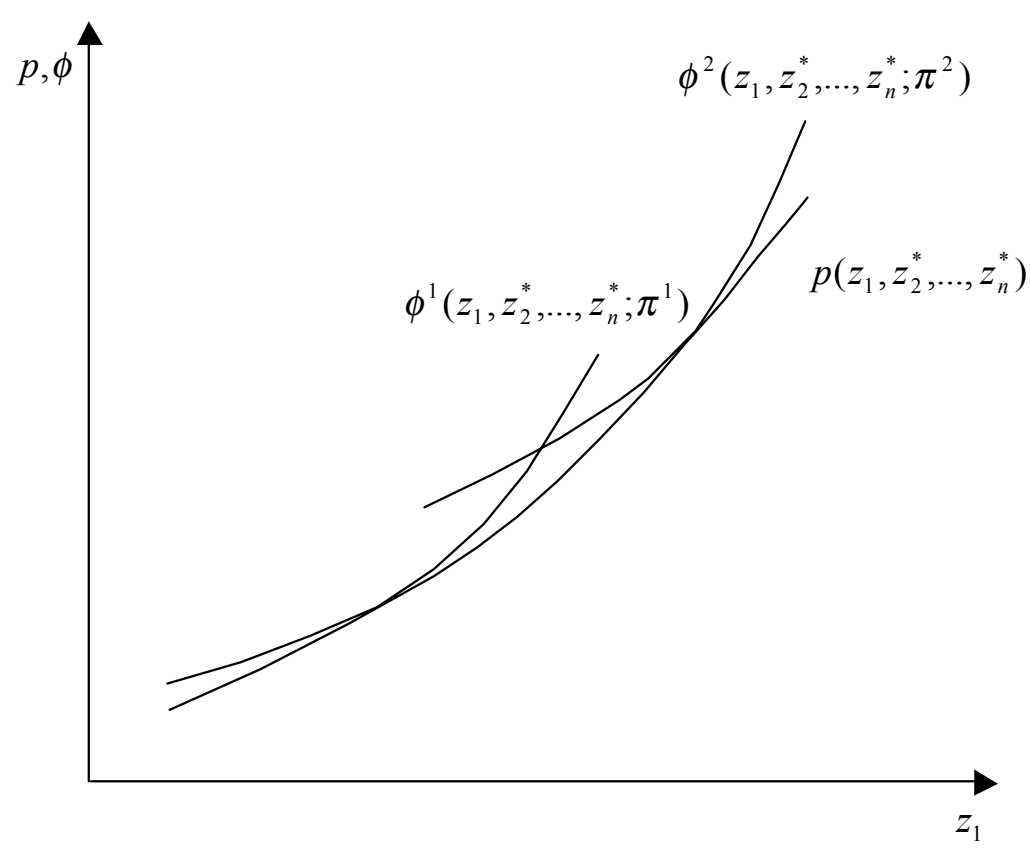

Para completar o modelo, devemos introduzir o setor de produção. Seja $C(z, N ; \beta)$ a curva de custo, onde $N$ é o número de unidades produzidas do bem composto e $\beta$ um parâmetro de características do produtor, então o lucro é dado por $\pi=p(z) N-C(z, N ; \beta)$. Cada produtor maximiza o lucro escolhendo $N$ e $z$ otimamente. As condições de primeira ordem requerem:

$p_{z i}=\frac{C_{z i}}{N}$

$\mathrm{e}$

$p(z)=C_{N}$

ou seja, cada produtor iguala o custo marginal de cada característica ao seu preço hedônico e produz novas unidades até que o custo marginal do bem composto iguale o seu preço.

Analogamente ao tratamento da demanda, definimos uma função de oferta $\phi\left(z_{1}, z_{2}, \ldots\right.$, $\left.z_{n} ; \pi, \beta\right)$, que indica os preços unitários que a firma está disposta a receber por diferentes 
designs, dado um lucro constante, quando o número de unidades é produzido otimamente:

$C_{N}=\phi\left(z_{1}, z_{2}, \ldots, z_{n} ; \pi, \beta\right)$

Derivando (7) em relação a $z_{i}$ :

$\phi_{z i}=\frac{C_{z i}}{N}$

onde $\phi_{z i}$ é o preço de reserva do produtor pela característica $i$.

Então, a maximização do lucro deve satisfazer:

$\phi\left(z_{1}, z_{2}, \ldots, z_{n} ; \pi, \beta\right)=p(z)$

e

$\phi_{z i}=p_{z i}$

Gráfico 2: Decisão do Produtor

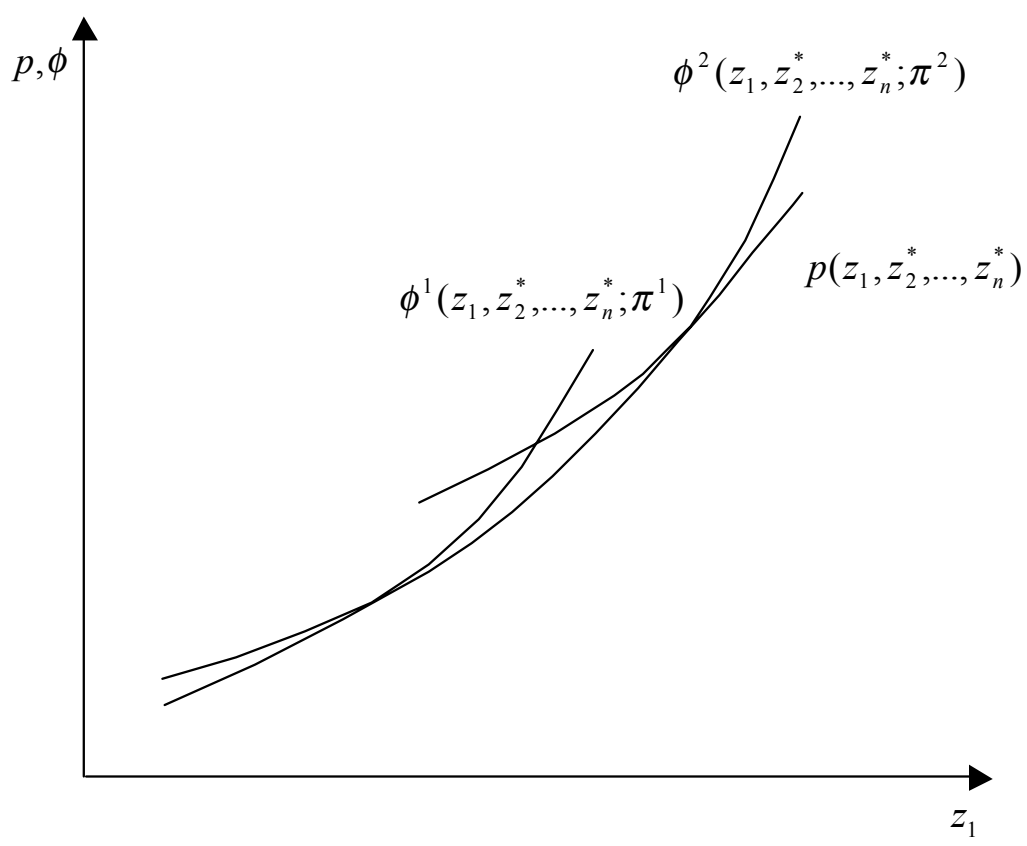


ou seja, um conjunto de curvas de oferta deve tangenciar a função de preços hedônicos, como mostra o Gráfico 2.

No equilíbrio de mercado, compradores e vendedores coincidem perfeitamente quando suas respectivas curvas de dispêndio e oferta se tangenciam. Assim, a função de preços hedônicos representa uma curva envoltória do conjunto de curvas de dispêndio e curvas de oferta, de acordo com o Gráfico 3.

Gráfico 3: Equilíbrio de Mercado

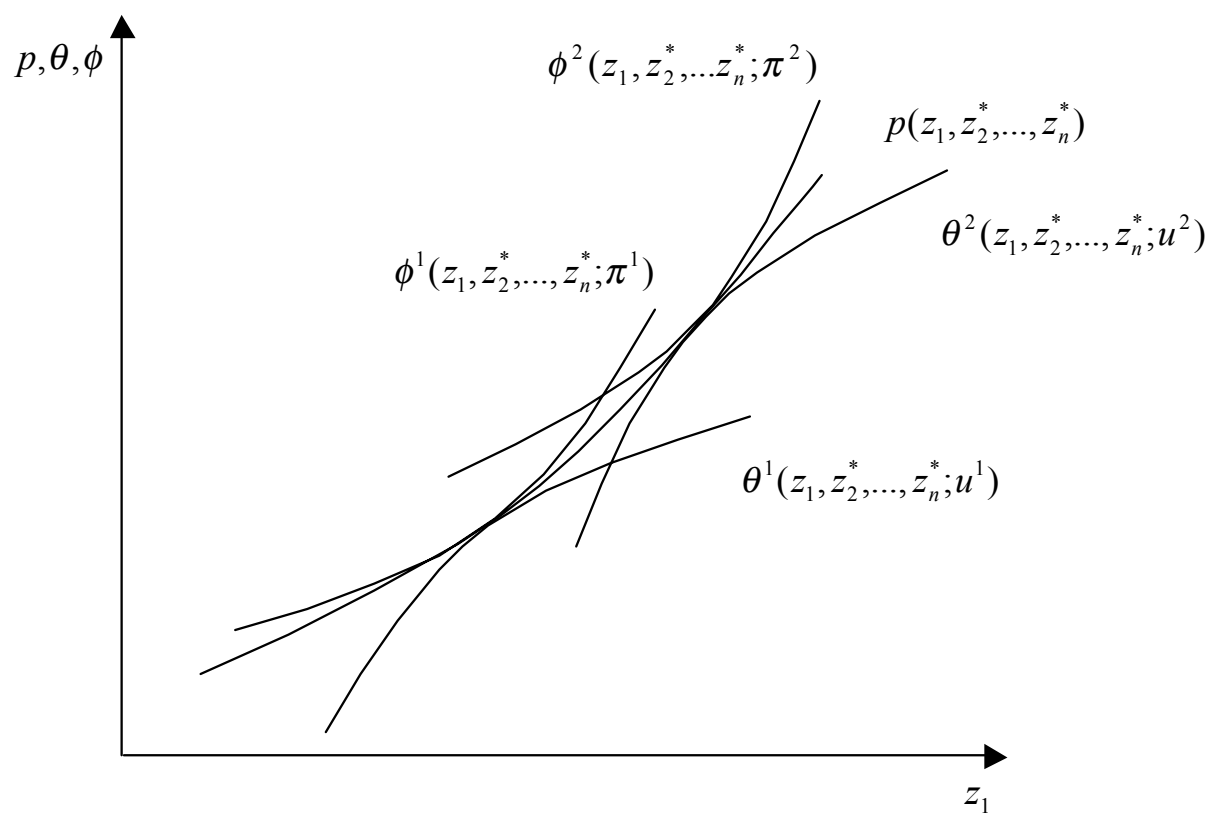

O resumo do comportamento do consumidor e do produtor, exposto acima, pressupõe a existência de um equilíbrio de mercado. Entretanto, a análise de equilíbrio depende do conhecimento da quantidade demandada $Q^{d}(z)$ e da quantidade ofertada de mercado $Q^{S}(z)$. Conhecidas as funções de oferta e demanda, o preço observado $p(z)$ é tal que $Q^{d}(z)=Q^{s}(z)$.

A quantidade demandada $Q^{d}(z)$ pode ser derivada utilizando a condição de equilíbrio do consumidor, equação (1), e a especificação de uma função de distribuição conjunta $F(y, \alpha)$ para a população de consumidores. O mesmo raciocínio serve para o lado da oferta. Encontramos $Q^{s}(z)$ a partir da condição de equilíbrio do produtor, equações (5) e (6), e de uma função de distribuição $G(\beta)$ para a população de produtores. 
Como Rosen (1974) observa, no caso de mercados para bens heterogêneos, a solução para $p(z)$ envolve um conjunto de problemas. A função de preços hedônicos geralmente é definida por uma equação diferencial não-linear, com a qual nem sempre é possível achar uma solução. É preciso impor um conjunto de restrições para o modelo, como, por exemplo, assumir renda ou preferências uniformes para os consumidores. Como consideramos um conjunto de características $\left(z_{1}, z_{2}, \ldots, z_{n}\right)$, o problema, então, envolve resolver $n$ equações diferenciais parciais. Dado esse conjunto de dificuldades, um caminho alternativo é proposto para estimar a função de oferta e demanda e a função de preços hedônicos.

Gráfico 4: Função de Preços Hedônicos

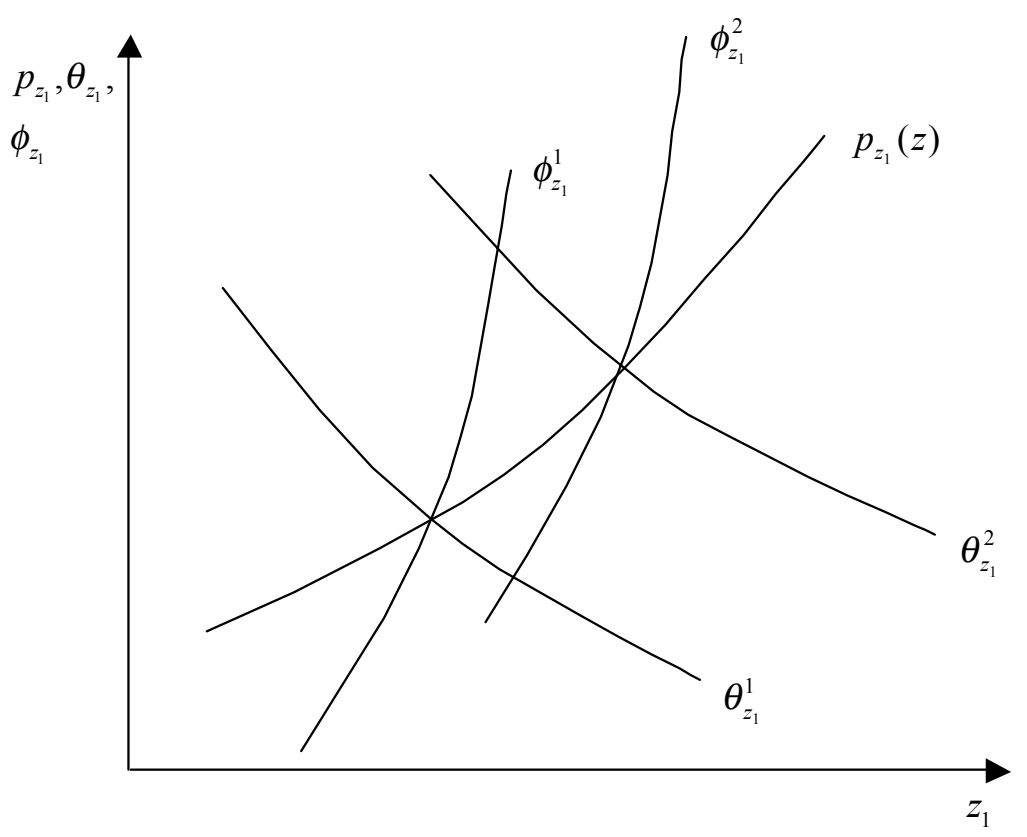

Como mostramos acima, $\theta_{z i}$ é o preço de reserva da demanda por quantidades adicionais de $z_{i}$, dada uma utilidade constante. Portanto, $\theta_{z i}(z)$ é o inverso de um conjunto de funções de demanda compensada para $z_{i}$. O preço hedônico marginal por $z_{i}$ é dado por $p_{z i}$, e a utilidade do consumidor é maximizada quando $\theta_{z i}=p_{z i}$. Um raciocínio similar aplica-se às firmas: $\phi_{z i}$ é o preço de reserva da oferta por uma unidade adicional de $z_{i}$, mantido o lucro constante, e reflete um conjunto de funções de oferta compensada para $z_{i}$. A receita marginal por $z_{i}$ é dada por $p_{z i}$, e a quantidade ótima de $z$ ocorre quando $\phi_{z i}=$ 
$p_{z i}$. No equilíbrio, a função de preço hedônico marginal por $z_{i}$ revela os pontos de interseção entre as curvas de oferta e demanda compensada, como mostra o Gráfico 4.

Com a informação sobre os preços negociados para os bens heterogêneos $p(z)$ e seus respectivos atributos $\left(z_{1}, z_{2}, \ldots, z_{n}\right)$, e supondo o conhecimento das características de cada família $\alpha$ e da tecnologia empregada por firma $\beta$, o modelo deve ser estimado em duas etapas. Primeiro, estimamos $p(z)$ pelo método tradicional de preços hedônicos, fazendo regredir o preço observado do bem heterogêneo sobre seus atributos:

$p(z)=p\left(z_{1}, z_{2}, \ldots, z_{n}\right)$

Em seguida, registramos os preços hedônicos marginais estimados $p_{z i}$ e os utilizamos como variáveis endógenas na resolução das equações simultâneas:

$p_{z i}=F^{i}\left(z_{1}, z_{2}, \ldots, z_{n} ; \alpha\right) \quad$ (demanda)

$p_{z i}=G^{i}\left(z_{1}, z_{2}, \ldots, z_{n} ; \beta\right) \quad$ (oferta)

O método de estimação de preços hedônicos, portanto, caminha no sentido inverso daquele que seria o mais intuitivo: derivar oferta e demanda e, em seguida, achar o preço que equilibra o mercado. A dificuldade apresentada no caso de mercados para bens heterogêneos é que $Q^{d}(z)$ e $Q^{s}(z)$ dependem de uma função $p(z)=p\left(z_{1}, z_{2}, \ldots, z_{n}\right)$. É preciso que compradores e vendedores se encontrem perfeitamente em todos os lugares no plano $n$ dimensional. Qualquer variação exógena nas quantidades de características compele a uma substituição em todos os lugares do plano.

Como estamos interessados somente nos preços hedônicos marginais das amenidades urbanas, limitar-nos-emos à primeira etapa do processo de estimação, fazendo regredir o valor do aluguel sobre as características de cada imóvel. Portanto, vamos estimar os preços marginais das amenidades, dada a suposição a priori de um equilíbrio. Neste caso, o trabalho serve apenas para revelar os preços hedônicos para um exato momento do tempo, conhecidas as quantidades de características. Entretanto, não podemos avaliar o preço futuro de um aluguel dado um choque exógeno qualquer que altere as condições 
de equilíbrio, como, por exemplo, a oferta de novas estações de metrô ou uma repentina queda na taxa de criminalidade.

$\mathrm{Na}$ próxima seção, trataremos das dificuldades enfrentadas para estimar a função de preços hedônicos. Relataremos as diversas opções adotadas e explicitaremos o método de estimação escolhido. 


\section{Método de Estimação}

\subsection{Problemas na Estimação de Preços Hedônicos}

A estimação da equação hedônica apresenta um grande conjunto de dificuldades. Primeiro, a teoria não determina uma forma funcional nem as variáveis relevantes para a estimação. Depois, a regressão esbarra freqüentemente no problema de multicolineariedade. E mais recentemente alguns autores vêm alertando para a presença de autocorrelação espacial dos resíduos. Faremos uma rápida revisão desses problemas, a partir da extensa literatura já produzida sobre o assunto, determinando o que nos parece ser mais apropriado para a execução do presente trabalho.

Tradicionalmente os estudos adotam uma forma linear ou log-linear para a função de preços hedônicos. Entretanto, a partir da década de 1980, começaram a surgir alguns trabalhos que adotam a transformação Box-Cox. Como a teoria não determina uma forma funcional específica, a vantagem da transformação Box-Cox é permitir que os próprios dados revelem a melhor forma funcional. Essa transformação utiliza um conjunto de parâmetros $\lambda_{n+1}$ sobre as variáveis, ${ }^{5}$ como segue abaixo:

$p^{\left(\lambda_{0}\right)}=\alpha_{0}+\alpha_{1} z_{1}^{\left(\lambda_{1}\right)}+\ldots+\alpha_{n} z_{n}^{\left(\lambda_{n}\right)}$,

onde

$z^{\left(\lambda_{i}\right)}=\frac{z^{\lambda_{i}}-1}{\lambda_{i}}$ se $\lambda_{i} \neq 0$, e $z^{\left(\lambda_{i}\right)}=\ln z$ se $\lambda_{i}=0$

A forma funcional é aquela definida pelos parâmetros de transformação estimados através de máxima verossimilhança.

O método Box-Cox tem a vantagem de gerar resíduos homocedásticos e simétricos. Entretanto, como o parâmetro de transformação é dependente das variáveis explicativas escolhidas, o método revela-se incapaz de atestar consistentemente a significância dos

\footnotetext{
${ }^{5}$ Esta é a apresentação da versão mais flexível. Ver Halvorsen e Pollakowski (1981).
} 
coeficientes estimados. ${ }^{6}$ Como estamos interessados justamente em revelar as amenidades urbanas que causam impacto sobre o preço dos aluguéis, ou seja, como desconhecemos as variáveis relevantes, parece-nos mais conveniente adotar um método de estimação que teste adequadamente a significância de cada uma delas.

O método Box-Cox ainda tem a desvantagem de gerar resultados não muito intuitivos. Como comenta Bowen et al. (2001), o coeficiente estimado expressa a variação no preço do aluguel transformado dada uma variação marginal no atributo transformado. Se adotamos uma forma linear, o preço hedônico marginal passa a ser uma constante. Embora essa alternativa esbarre na crítica de que a função de preços hedônicos seja nãolinear, essa simplificação será útil para dedicarmos maior atenção a outros problemas estatísticos. $^{7}$

Ainda sobre o problema de especificação, precisamos fazer algumas observações sobre as variáveis explicativas que devem entrar na função de preços hedônicos. Embora o modelo hedônico não determine a priori as variáveis relevantes, muitos estudos ignoram alguns conceitos clássicos da economia urbana. As contribuições de Alonso (1964), Mills (1972), Fujita e Ogawa (1982), entre outros, evidenciam o papel da localização dos imóveis para a formação de um gradiente de preços. Segundo estas, à medida que o imóvel se afasta do centro de negócios, o preço da moradia deve compensar o aumento nos custos de transporte.Voltaremos a esta questão de forma mais aprofundada na seção 4. Por enquanto, é relevante apenas destacar a necessidade de incluir um vetor que expresse o efeito acessibilidade.

A teoria econômica sugere também a inclusão da oferta de bens públicos e a qualidade da vizinhança na análise sobre o preço de moradia. Esse é justamente o foco do presente trabalho, e talvez um dos tópicos mais problemáticos na literatura sobre o modelo hedônico para habitação. Muitos estudos vêm apresentando resultados insignificantes ou mesmo invertidos para os coeficientes das amenidades urbanas. O problema principal reside na dificuldade de mensurar exatamente aquilo que está sendo consumido pelos moradores. Andersson (1997) apresenta uma pesquisa com os fatores em ordem de importância que determinam a escolha residencial dos agentes. Em sua maioria, os

\footnotetext{
${ }^{6}$ Ver Andersson (1997).

${ }^{7} \mathrm{Na}$ verdade, experimentamos outras formas pré-especificadas, mas a versão linear foi sempre superior.
} 
principais atributos eleitos são de natureza intangível, como o conceito de aprazibilidade, por exemplo, o que dificulta a escolha de uma proxy para seus efeitos. $\mathrm{Na}$ tentativa de preencher esses fatores, podemos selecionar uma variável bastante correlacionada com alguma outra, o que leva ao problema de multicolinearidade. $\mathrm{Ou}$ uma proxy pode igualmente estar captando efeitos distintos, muitos vezes ambíguos, o que impacta na significância do coeficiente.

O problema de medida ainda está relacionado à exata fronteira de impacto das amenidades. Geralmente os dados são fornecidos para alguma fronteira administrativa município, distrito ou bairro -, o que não condiz necessariamente com o alcance das externalidades provocadas. A falta de informação sobre a qualidade da vizinhança é um dos motivos apontados para a presença de autocorrelação espacial. ${ }^{8} \mathrm{O}$ aluguel de um imóvel pode estar correlacionado com o aluguel de seus vizinhos, porque, na verdade, eles comungam as mesmas amenidades urbanas.

Como observamos, os estudos empíricos sobre preços hedônicos para habitação enfrentam regularmente o problema de multicolineariedade. As conseqüências, nesse caso, são bastante indesejadas: torna-se muito difícil identificar separadamente o efeito das variáveis envolvidas; os parâmetros estimados tendem a apresentar baixa significância; e qualquer variação no número de observações ou no quadro das variáveis explicativas pode alterar sensivelmente os coeficientes estimados. A solução para esse caso envolve a inclusão de mais informação no banco de dados - que nem sempre é disponível - ou a adoção de técnicas para correção da não-ortogonalidade das variáveis explicativas. Seguindo os passos de Kain e Quinley (1970) e Can (1990), apresentaremos uma especificação alternativa que inclui a técnica de análise fatorial.

$\mathrm{Na}$ literatura mais recente, alguns autores começaram a atentar para a presença de autocorrelação espacial nos resíduos. ${ }^{9}$ Dada a natureza geográfica da pesquisa, os imóveis podem apresentar algum grau de dependência espacial. Isso pode ocorrer pela falta de discriminação das variáveis ambientais, como exposto anteriormente, ou pela presença de efeitos spill-over entre imóveis. A quebra na hipótese de independência entre observações provoca a estimação de parâmetros viesados e a determinação de

\footnotetext{
${ }^{8}$ Ver Can (1990) e Andersson (1997).

${ }^{9}$ Ver Can (1990) e Dubin (1992).
} 
níveis de significância enganosos. Portanto, é necessária a adoção de testes para averiguação de uma possível dependência espacial entre as observações. Caso o resultado dos testes seja positivo, deve-se reespecificar o modelo.

Resumindo, a regressão da função de preços hedônicos envolve um grande conjunto de problemas estatísticos, ocasionando, geralmente, a estimação de parâmetros pouco confiáveis. Dessa forma, preferimos não prosseguir numa investigação mais adiante do modelo hedônico. A estimação de uma função de demanda para amenidades, além de envolver outro conjunto de problemas, necessita de robustez nos preços marginais estimados. Limitar-nos-emos à primeira etapa do modelo apresentado por Rosen (1974), a estimação da função de preços hedônicos, que já apresenta desafios suficientes para a pesquisa.

\subsection{Especificação e Teste}

Feitas as considerações necessárias sobre a forma funcional e as variáveis relevantes, a equação (9) será especificada da seguinte maneira:

$p(S, A, E)=\alpha_{0}+\alpha_{1} S+\alpha_{2} A+\alpha_{3} E+u$,

onde $S$ representa um vetor de características estruturais do imóvel, $A$ um vetor que designa acessibilidade e $E$ um vetor de variáveis ambientais.

Além da especificação tradicional, vamos estimar uma forma alternativa, incluindo análise fatorial. $\mathrm{O}$ método busca solucionar o problema de multicolinearidade, criando fatores que são transformações lineares das variáveis independentes, de maneira que sejam ortogonais ou quase ortogonais entre si. Utilizaremos a análise fatorial apenas para as variáveis ambientais, mantendo o vetor original de variáveis estruturais e de acessibilidade.

A primeira etapa resume-se à obtenção de uma solução linear para um conjunto de variáveis em termos de fatores hipotéticos, como segue: 
$z_{i}=\sum_{j} a_{i j} F_{j}+d_{i} U_{i}$

onde $z_{i}$ é a versão normalizada do atributo $i, F_{j}$ é o fator comum $j, a_{i j}$ é a carga fatorial, $U_{i}$ é o fator singular $i$ e $d_{i}$ é o parâmetro correspondente.

O número de fatores comuns pode ser reduzido em relação ao número de variáveis iniciais. Dependendo da quantidade de restrições em relação ao número de incógnitas, as cargas fatoriais não são unicamente determinadas. Pelo contrário, existem infinitas formas de construção de fatores ortogonais ou quase ortogonais. Este problema de indeterminação permite a seleção arbitrária de alguma solução mais favorável à interpretação dos fatores. A partir de uma extração inicial, podemos rotar os fatores para selecionar a solução "preferida". ${ }^{10}$ Adotamos o método de rotação varimax, que aumenta a carga fatorial de cada variável para um fator específico. Com isso, podemos melhor definir a característica de cada fator. Ou seja, como abandonamos as variáveis iniciais, desejamos criar fatores que apresentem alguma interpretação econômica razoável. A rotação varimax facilita essa construção, pois maximiza a variância de uma variável inicial sobre o mesmo fator.

$\mathrm{Na}$ segunda etapa, os fatores devem ser descritos em função das variáveis. Como o número de fatores é inferior ao de variáveis, a matriz de cargas fatoriais é singular. $\mathrm{O}$ procedimento mais adequado neste caso é a simples regressão pelo método de mínimos quadrados. A regressão linear é expressa da seguinte forma:

$$
F_{j}=\sum_{i} \beta_{j i} z_{i}+\varepsilon_{j}
$$

Conhecidos os fatores, podemos então estimar a função de preços hedônicos, como segue:

$$
P=\alpha_{0}+\alpha_{1} S+\alpha_{2} A+\sum_{j=3}^{J} \alpha_{j} F_{j}\left(z_{1}, z_{2}, \ldots, z_{I}\right)+u
$$

\footnotetext{
${ }^{10}$ Ver Harman (1967).
} 
O modelo pode, ainda, ser reespecificado de acordo com a presença de dependência espacial. Existem duas maneiras para incorporar esse efeito à especificação tradicional. A primeira é o modelo com autocorrelação nos resíduos:

$p=\alpha Z+u$,

com

$u=\gamma W u+e$,

onde $\gamma$ é um coeficiente auto-regressivo espacial, $W$ uma matriz de pesos espaciais e $e$ um termo de erro padrão.

A segunda forma adiciona uma variável dependente espacialmente defasada na especificação tradicional:

$p=\rho W p+\alpha Z+u$

A segunda alternativa apresenta um significado econômico mais explícito. Estamos assumindo que o valor de um aluguel é influenciado pelos aluguéis vizinhos. De fato, no mercado imobiliário é comum valorar aluguéis baseando-se na precificação dos imóveis próximos. A presença de dependência espacial ainda pode ser explicada por variáveis ambientais omitidas. Neste caso, imóveis próximos comungam a mesma qualidade de vizinhança, e o efeito das variáveis ambientais omitidas é captado no coeficiente da variável dependente espacialmente defasada. Mostraremos na seção 6 que, à medida que incorporamos variáveis de conteúdo geográfico, a significância dos coeficientes de autocorrelação espacial tende a diminuir.

A potencial ocorrência de dependência espacial pode ser avaliada utilizando-se o teste de Multiplicadores de Lagrange (LM). O teste LM é baseado na estimação por máxima verossimilhança. Contudo, o teste não necessita da estimação do modelo alternativo. $\mathrm{O}$ 
modelo restrito sem um parâmetro de dependência espacial é assumido como hipótese nula. Assim, podemos proceder ao teste LM pelo método de mínimos quadrados. ${ }^{11}$

A hipótese de dependência espacial é incorporada às equações (16) e (17) através da matriz de pesos generalizados $W$. A matriz de dimensão $n x n$ avalia o grau de vizinhança entre as observações. Diferentemente dos modelos de séries de tempo, a construção de um operador defasado para fenômenos é um tanto arbitrária. ${ }^{12}$ Como trabalhamos com unidades espaciais na forma de pontos, adotaremos medidas diretas de distância entre as observações, da seguinte forma:

$W 1: w_{i j}=d_{i j}^{-1}$

$W 2: w_{i j}=d_{i j}^{-2}$

onde $d_{i j}{ }^{-1}$ é o inverso da distância entre o domicílio $i$ e o domicílio $j$ e $d_{i j}{ }^{-2}$ é ao inverso do quadrado da distância.

$\mathrm{Na}$ seção 6, apresentaremos os resultados das estimações para a função de preços hedônicos, utilizando as variáveis ambientais originais e a construção dos fatores, equações (12) e (15). O trabalho ainda envolve três versões para cada caso, dependendo do modelo de acessibilidade assumido, que discutiremos a seguir.

${ }^{11}$ Ver Anselin (1988).

${ }^{12}$ Idem. 


\section{Acessibilidade}

Como já havíamos mencionado, um estudo empírico sobre o modelo hedônico para habitação não pode estar desprovido de um embasamento teórico em economia urbana. Um dos motivos é o papel determinante da localização na formação de preços de imóveis e aluguéis. Para selecionar o vetor que capte o efeito da acessibilidade na função hedônica, precisamos primeiro considerar as diferentes configurações urbanas que mais se aproximam do nosso objeto de estudo.

\subsection{Configuração Urbana Monocêntrica}

A economia urbana tradicional baseia-se num modelo de cidade circular com um único centro de negócios responsável por todo o emprego local. O modelo monocêntrico foi desenvolvido nos trabalhos pioneiros de Alonso (1964), Mills (1972) e Wheaton (1974), com sua apresentação sendo consolidada em Brueckner (1987). Nesse modelo, o valor do aluguel e a densidade estrutural da cidade são funções negativas da distância ao centro de negócios. A região central é determinada $a d$ hoc e representa um pico no gradiente de preços de aluguel, como podemos observar no Gráfico 5 .

Em geral, os estudos empíricos sobre o modelo hedônico para habitação assumem a forma urbana monocêntrica, incorporando uma variável de distância linear ou logarítmica de cada domić́lio ao centro de negócios $A_{i}=d_{i}$ ou $A_{i}=\ln \left(d_{i}\right)$. É evidente que nem todas as cidades apresentam essa configuração. Muito pelo contrário, especialmente nas grandes metrópoles observamos formatos multicêntricos. As cidades, em geral, têm uma origem monocêntrica, mas, com a expansão territorial, os custos de transporte induzem o surgimento de novos centros. É possível, ainda, que as cidades não apresentem crescimento radial, pois características topográficas podem limitar essa expansão. Um outro aspecto bastante relevante é que o pico do gradiente de preços nem sempre se localiza nos centros de negócios. A presença de amenidades ou "desamenidades" urbanas pode modificar essa estrutura. Um exemplo clássico é a deterioração dos centros históricos. Nesse caso, o gradiente de preços, ao invés de apresentar um formato monotonamente decrescente, apresentaria, a partir da origem, um movimento ascendente, para depois assumir uma inclinação negativa. 
Gráfico 5: Modelo Monocêntrico

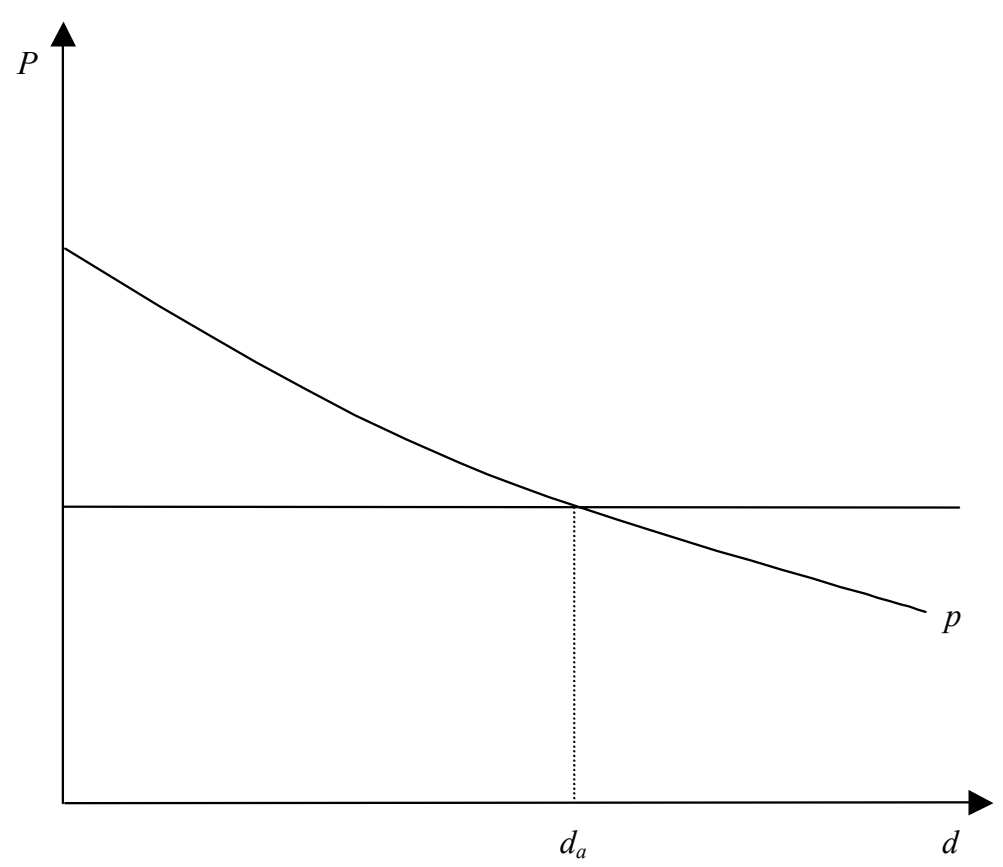

A cidade de São Paulo apresenta algumas vantagens para a adoção de um formato monocêntrico. Primeiro, encontramos um centro histórico bem definido, tradicionalmente locus das atividades de comércio e serviços, e podemos assumir a Praça da Sé como marco fundamental. Depois, a cidade não sofreu nenhuma restrição geográfica que impedisse sua configuração bastante circular. Entretanto, observando a distribuição dos postos de trabalho por distrito no município, percebemos que a incidência de emprego não se limita ao antigo centro de negócios, como mostra o Mapa 1.

O quadro da esquerda, abaixo, apresenta o total de empregos por distrito. Observamos uma aglomeração em torno do centro histórico, na Praça da Sé, mas com uma proeminente expansão na direção oeste. A avenida Paulista, por se localizar muito próxima do centro histórico, pode, para efeito de cálculos de distância, ser considerada parte deste núcleo. O único fato indesejado para a análise de emprego por distrito é que a avenida se localiza na fronteira dos distritos Bela Vista e Jardim Paulista. 
Mapa 1: Número de Empregos Totais e Importação/Exportação de Empregos por Distrito - São Paulo

\section{FONTES:}

Eb barada a pa Mirde dadas:

EG barada Z Pa Hir de dadas:
LU WWE 2002: SEWPLA 2002: IEGE 2000
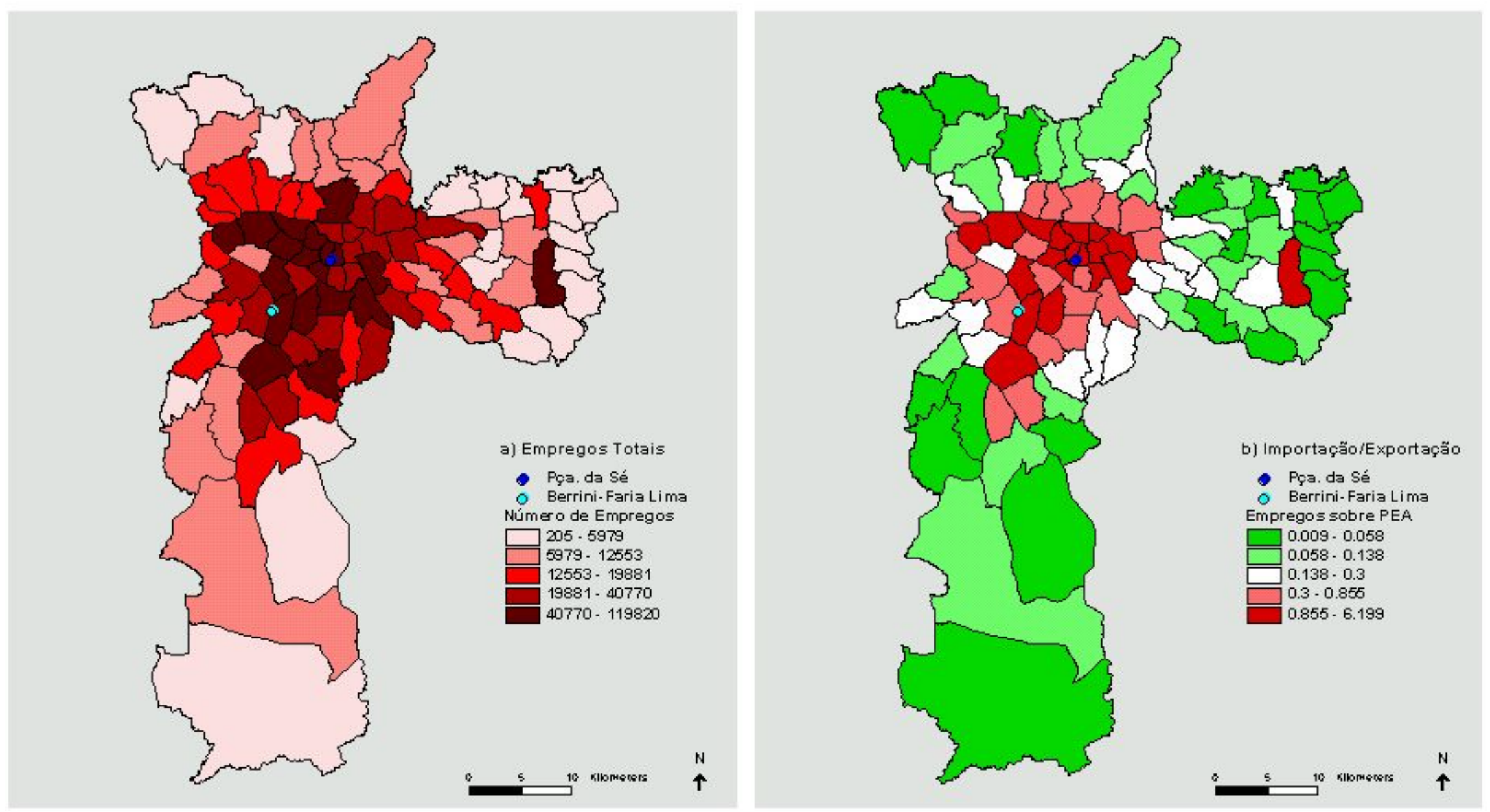
Encontramos ainda um outro cluster de empregos a sudoeste, na região das avenidas Berrini e Faria Lima. Este ponto pode ser adotado como um novo centro de negócios, o que indicaria um formato duocêntrico para a cidade. Entretanto, o formato com dois centros ainda é uma boa simplificação, visto que os empregos não estão restritos a essas áreas.

Como, na verdade, estamos interessados no fluxo de pessoas e no impacto dos custos de transporte, uma melhor proxy de avaliação é a razão empregos sobre população economicamente ativa. Dessa forma, podemos separar os distritos eminentemente importadores de mão-de-obra dos demais. O quadro da direita, abaixo, mostra uma relação um pouco mais concentrada. Apenas os distritos em vermelho forte apresentam uma razão acima de 1. Contudo, continuamos destacando os mesmos endereços, o centro histórico, o novo centro e ainda a presença de um outlier, representado pelo Jardim José Bonifácio, na região leste. A Tabela 1 resume as informações para os dez principais distritos importadores de mão-de-obra.

Tabela 1: Emprego Total por Distrito - São Paulo

\begin{tabular}{clrrr}
\hline Classif. & \multicolumn{1}{c}{ Distritos } & $\begin{array}{c}\text { Emprego } \\
\text { total }\end{array}$ & $\begin{array}{c}\text { Total } \\
\text { acumulado }\end{array}$ & Total/PEA \\
\hline 1 & Sé & 91,520 & $3.70 \%$ & 6.1993 \\
2 & Barra Funda & 50,127 & $5.72 \%$ & 5.5796 \\
3 & República & 103,116 & $9.89 \%$ & 2.8311 \\
4 & Santo Amaro & 119,757 & $14.73 \%$ & 2.7275 \\
5 & Bela Vista & 119,820 & $19.57 \%$ & 2.5365 \\
6 & Vila Leopoldina & 47,755 & $21.50 \%$ & 2.4997 \\
7 & Pinheiros & 94,555 & $25.32 \%$ & 2.0798 \\
8 & Pari & 20,120 & $26.14 \%$ & 1.9758 \\
9 & Brás & 33,907 & $27.51 \%$ & 1.9177 \\
10 & Itaim Bibi & 110,842 & $31.99 \%$ & 1.8813 \\
\hline \hline Fonte: Sempla (2002). & & &
\end{tabular}

Observamos que os seis distritos que incorporam os dois centros assinalados, Sé, República e Bela Vista, para o centro histórico, e Santo Amaro, Pinheiros e Itaim Bibi, para o centro novo, encontram-se na lista. O grau de aglomeração ainda é baixo quando comparado ao índice de empregos total do município. Os dez principais distritos importadores de mão-de-obra representam apenas $32 \%$ do total de empregos na cidade. Entretanto, é importante salientar que os dados para emprego fornecidos pela SEMPLA 
(2002) apresentam um viés de não-aglomeração, isso porque não contabilizam os empregos no setor de administração pública, concentrados no centro histórico, e desconsideram o mercado informal. Embora não existam números precisos sobre a distribuição espacial do setor informal, este parece também estar concentrado no centro histórico.

A dispersão do emprego total é explicada em parte pela presença de atividades industriais fora dos grandes centros e de pequenos comércios de bairro. $\mathrm{O}$ centro de negócios deve ser caracterizado pela concentração do setor de serviços. Atividades industriais exigem lotes maiores e não podem concorrer com outras firmas pelo custo do terreno. Por outro lado, o pequeno comércio varejista apresenta um custo de transporte muito elevado, que não compensa possíveis ganhos de aglomeração, direcionando o setor para locais mais próximos dos consumidores.

No Mapa 2, utilizamos novamente os dados da SEMPLA (2002), considerando agora apenas o setor de serviços. Como podemos observar, a concentração de atividades permanece relativamente a mesma. Destacamos a menor participação dos distritos a leste do centro histórico - Brás, Mooca e Belém -, tradicionais redutos industriais, e, no caso do Brás, a presença do comércio de "pechinchas".

A Tabela 2 resume as informações do mapa para os dez principais distritos importadores de mão-de-obra do setor de serviços. Como podemos observar, não existem grandes alterações no quadro. Os três distritos que compõem o centro velho e os três distritos que compõem o centro novo permanecem entre os dez primeiros. Os distritos a oeste - Barra Funda e Vila Leopoldina - e ainda o distrito no extremo leste Jardim José Bonifácio - apresentam papel destacado. O grau de concentração para os dez maiores distritos, neste caso, é um pouco maior, superando os $46 \%$. 
Mapa 2: Número de Empregos no Setor de Serviços e

\section{FONTES:}

Importação/Exportação de Empregos por Distrito - São Paulo

E七 tarada z pa rir de dadas:

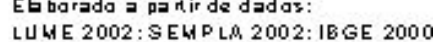
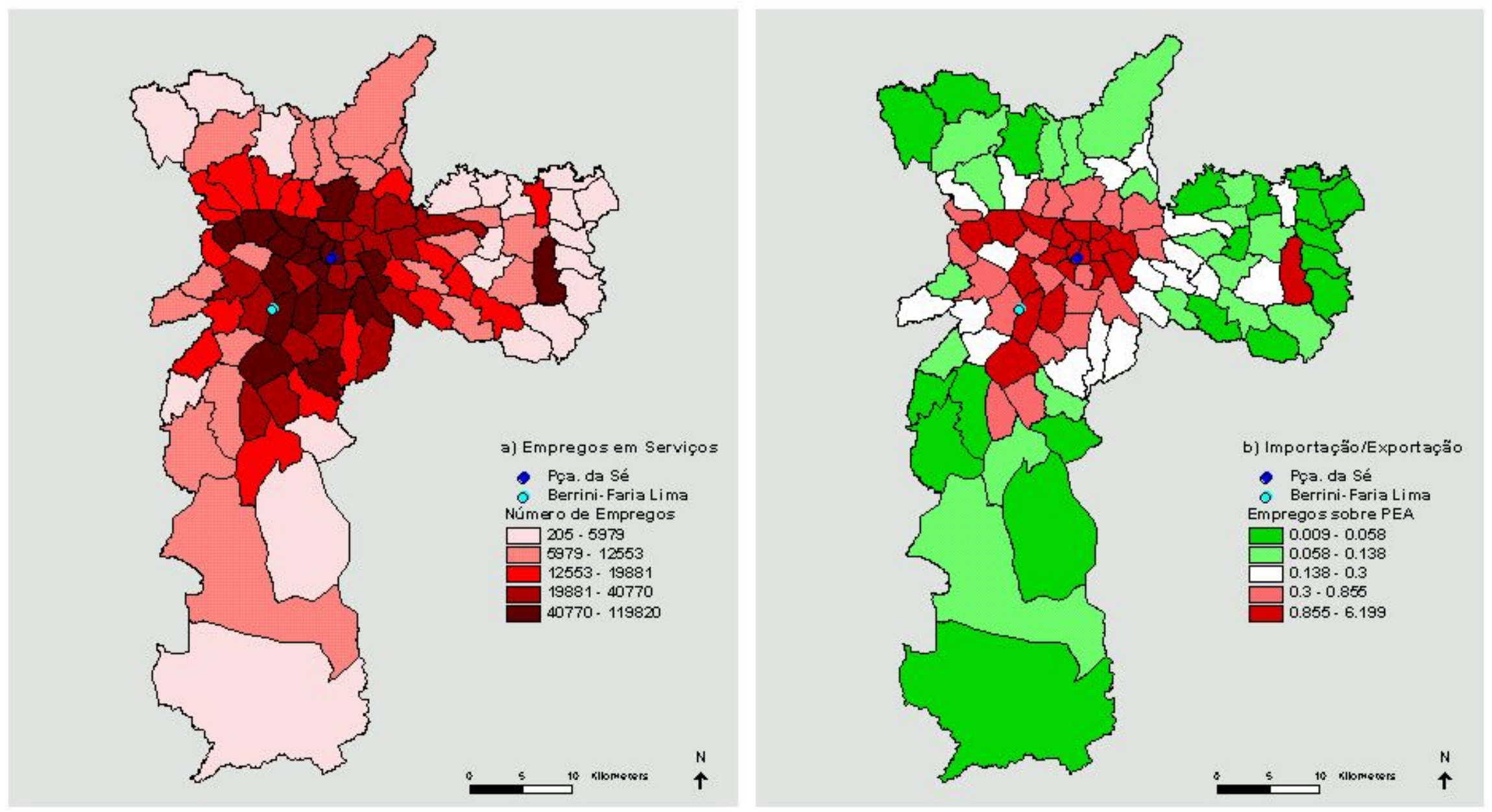
Tabela 2: Emprego no Setor de Serviços por Distrito - São Paulo

\begin{tabular}{clrrr}
\hline Classif. & \multicolumn{1}{c}{ Distritos } & $\begin{array}{c}\text { Emprego } \\
\text { Serviços }\end{array}$ & $\begin{array}{c}\text { Serviços } \\
\text { acumulados }\end{array}$ & Serviços/PEA \\
\hline 1 & Sé & 67,465 & $5.52 \%$ & 4.5699 \\
2 & Barra Funda & 25,507 & $7.60 \%$ & 2.8392 \\
3 & Bela Vista & 101,406 & $15.90 \%$ & 2.1467 \\
4 & República & 72,173 & $21.80 \%$ & 1.9816 \\
5 & Vila Leopoldina & 31,195 & $24.35 \%$ & 1.6329 \\
6 & Consolação & 54,023 & $28.77 \%$ & 1.3526 \\
7 & Pinheiros & 51,143 & $32.95 \%$ & 1.1249 \\
8 & Itaim Bibi & 59,151 & $37.79 \%$ & 1.0040 \\
9 & Santo Amaro & 43,931 & $41.38 \%$ & 1.0005 \\
10 & Jardim José Bonifácio & 60,872 & $46.36 \%$ & 0.8017 \\
\hline \hline
\end{tabular}

Fonte: SEMPLA (2002).

Embora a região central ainda represente um papel importante como locus de emprego no Município de São Paulo, a opção tradicional pelo modelo monocêntrico parece um pouco limitada. É evidente a participação do centro de serviços, complexo Berrini-Faria Lima, na atividade econômica da cidade, como já se havia discutido em Biderman (2001). Portanto, devemos avançar um pouco mais nessa questão e analisar modelos alternativos para a seleção do vetor de acessibilidade.

\subsection{Configuração Urbana Duocêntrica}

Muitos estudos teóricos já foram desenvolvidos com o objetivo de modelar áreas metropolitanas não-monocêntricas. No trabalho de Fujita e Ogawa (1982), a configuração urbana passa a ser determinada endogenamente pelo modelo. Firmas e famílias competem entre si na decisão de localização e enfrentam trade-off's por estarem mais ou menos próximas dos respectivos centros. Para as firmas, os ganhos de aglomeração são contrapostos aos crescentes custos de produção e, no caso das famílias, o custo de transporte é compensado pela queda no valor dos aluguéis. Este modelo é um tanto mais complexo, mas, de qualquer forma, reproduz o gradiente de preços negativamente inclinado com origem no centro (ou centros) de negócios.

No Gráfico 6, observamos o caso de uma cidade duocêntrica. Na parte 6(a), é apresentada a configuração urbana, onde $B D$, business district, representa a região na qual se localizam exclusivamente as firmas e $R A$, residential area, a região de 
localização exclusiva das famílias. $\mathrm{Na}$ parte 6(b), são ilustrados os ganhos de aglomeração das firmas através da função $F(d)$. Podemos observar que à medida que nos aproximamos dos centros os ganhos são maiores. O mesmo efeito é notado para os salários $W(d)$ e para os aluguéis $P(d)$, partes $6(\mathrm{c})$ e $(\mathrm{d})$.

\section{Gráfico 6: Modelo Duocêntrico}

a)

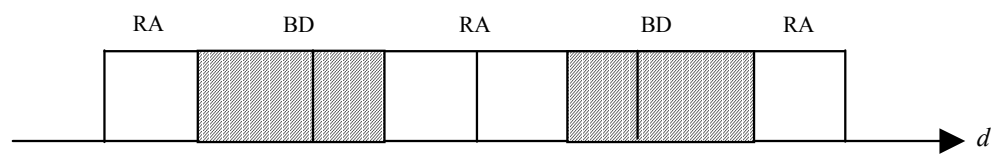

b)

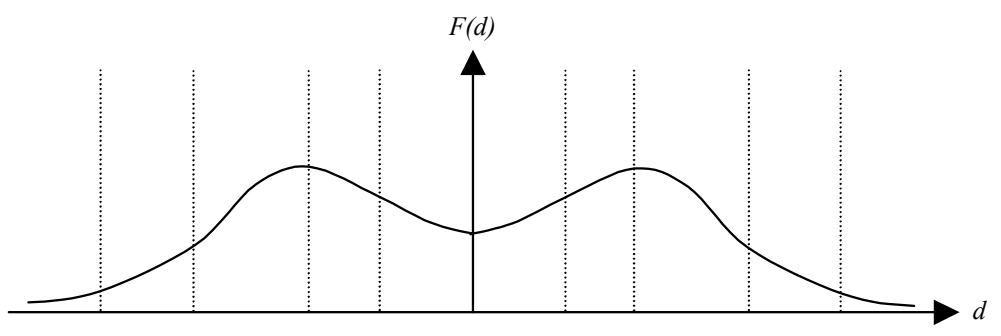

c)

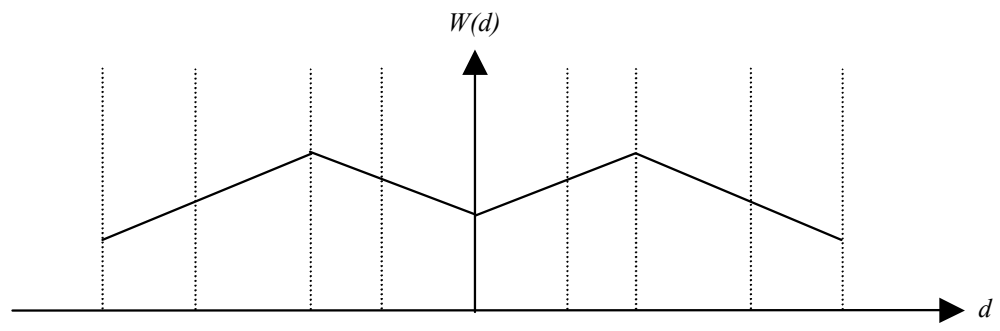

d)

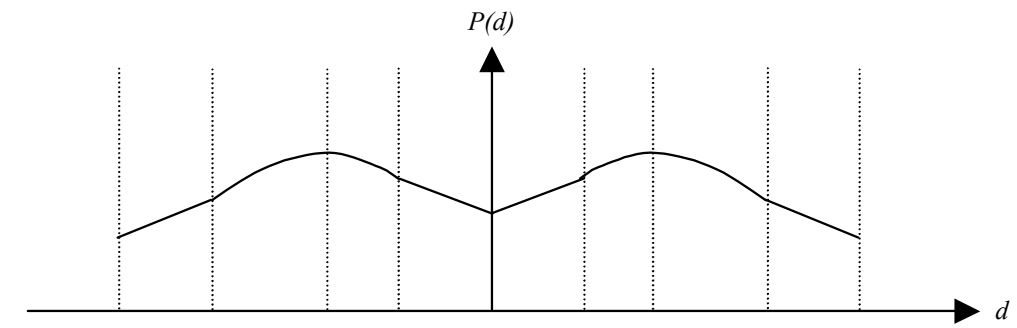

A incorporação de um vetor de acessibilidade na equação hedônica, neste caso, ainda é pouco discutida na literatura. Plaut (1998) adota simplificadamente duas medidas de distância para os respectivos centros: $\alpha A_{i}=\alpha^{l} d_{i}{ }^{1}+\alpha^{2} d_{i}{ }^{2}$, onde $\alpha^{n}$ é o coeficiente da distância ao centro $n$ e $d^{n}$ é a distância ao centro $n$. Entretanto, esta interpretação não parece coerente com o modelo de Fujita e Ogawa (1982), já que a distância de ambos os centros afetaria o preço de todas as moradias. Segundo o modelo, as famílias trabalham 
exclusivamente nos centros mais próximos. O valor de salários e aluguéis decresce na mesma proporção, independentemente da direção. Uma medida de acessibilidade para o caso duocêntrico deveria retratar apenas a distância para o centro mais próximo, como $A=\min \left(d_{i}{ }^{1}, d_{i}{ }^{2}\right)$. Considerando que pode haver diferença na altura dos interceptos das regiões centrais, devemos distinguir no entorno de que vizinhança localiza-se a observação, incluindo uma dummy relativa à proximidade a um dos dois centros.

Temos agora um quadro completo das estimações a serem realizadas. Procuraremos extrair os preços hedônicos marginais das amenidades urbanas através das variáveis ambientais originais ou de fatores. Para cada caso serão apresentadas três versões de acessibilidade: o caso monocêntrico, o caso duocêntrico com duas distâncias e o caso duocêntrico com distância mínima. Antes de procedermos às estimações, resta ainda apresentar o banco de dados. 


\section{O Banco de Dados}

\subsection{Amostra de Domicílios}

Os dados necessários para a estimação da equação (12) foram, em parte, obtidos diretamente de fontes primárias e, em parte, gerados através da utilização de um sistema geográfico de informação (SIG). Os dados agrupados no SIG apresentam três formas distintas de representatividade espacial: pontos, distância entre pontos e polígonos. As informações sobre imóveis estão expressas na forma de pontos no espaço, sendo que cada ponto representa um domicílio ao qual está associado um valor de aluguel e um conjunto de características estruturais. As informações sobre acessibilidade e um grupo de amenidades estão expressas na forma de distância entre pontos. Isto é feito calculando-se a distância em linha reta entre uma observação e um outro ponto de referência (e.g. a distância de cada domicílio ao centro de negócios). Um último tipo de informação é aquela representativa de um território específico, um polígono - no presente estudo, um distrito correspondente no município de São Paulo. Quando um domicílio é georeferenciado, automaticamente assume o valor do polígono que o circunda. Portanto, para grande parte das amenidades, assumimos o distrito como a vizinhança relevante para a caracterização do imóvel. Como já discutimos, essa decisão arbitrária embute um problema de erro de medida, pois os distritos não são homogêneos o suficiente para retratarmos com o mesmo valor domicílios estabelecidos em lugares diferentes do mesmo distrito.

As informações sobre imóveis foram extraídas da "Pesquisa de Orçamentos Familiares" (POF) produzida pela Fundação Instituto de Pesquisas Econômicas - Fipe (1999). São ao todo 497 observações, cada uma com o valor do aluguel pago pela família e diversas características estruturais do imóvel. Esta amostra foi georeferenciada de acordo com o endereço presente na POF, como mostra o Mapa 3. 


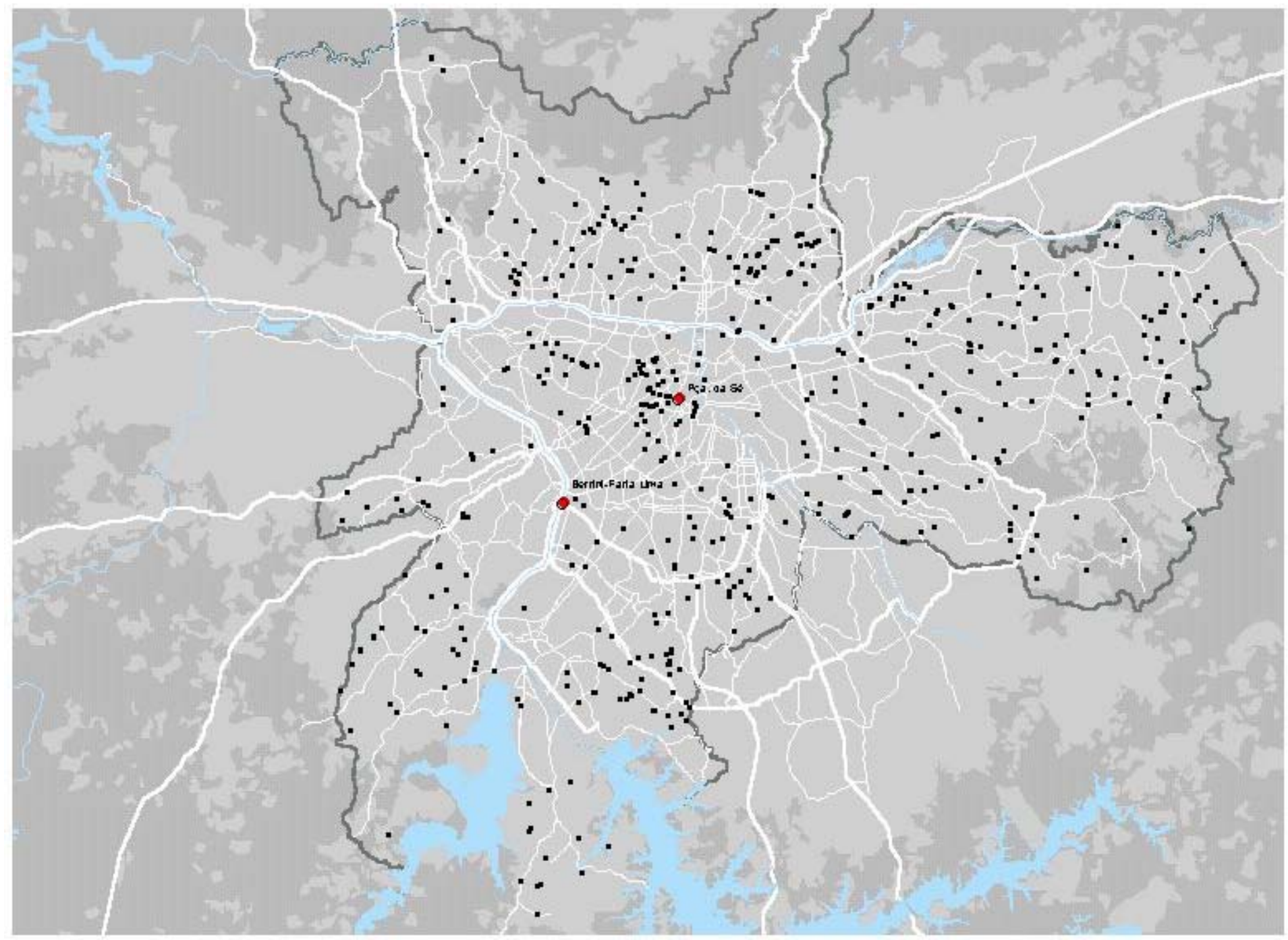

Mapa 3:

Amostra de

Domicílios -

São Paulo

- Dom icílios

- Pça.da Sé

- Berrini-Faria Lima Rios

Represas

Avenidas

Viário Regional

Lim ite Municipa

Mancha Urbana

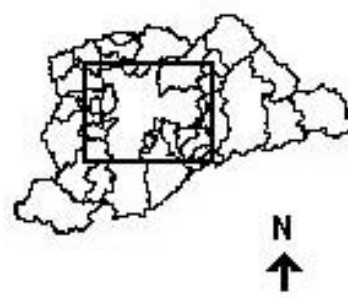

Eubarada a pa hir de dadas: ULWE 2002: 
A adoção do valor do aluguel, em vez do valor de compra e venda do imóvel, parecenos mais conveniente. $\mathrm{O}$ valor do imóvel expressa uma expectativa futura, pois seu cálculo é baseado no valor presente de um número infinito de aluguéis. Portanto, alterações espaciais futuras, ou sua simples expectativa, podem impactar o valor venal do imóvel. Como nossa análise limita-se às características espaciais em um dado período de tempo, o valor do aluguel não capta esse distúrbio.

Tabela 3: Variável Independente e Variáveis de Controle

\begin{tabular}{|c|c|c|c|}
\hline Variável & Descrição & Média & Dv-padrão \\
\hline ALUG & aluguel em R\$ & 353.20 & 211.55 \\
\hline SALA & $\mathrm{n}^{\mathrm{o}}$ de salas & 0.7042 & 0.5110 \\
\hline GARAG & $\mathrm{n}^{\mathrm{o}}$ de garagens & 0.3581 & 0.5164 \\
\hline DORM_AG & $\mathrm{n}^{\mathrm{o}}$ de dormitórios $+0.5^{*}$ dorm. de empregada & 1.5755 & 0.8223 \\
\hline $\mathrm{COZ} \_\mathrm{AG}$ & $\mathrm{n}^{\mathrm{o}}$ de cozinhas $+0.5^{*}($ copas + lavanderias $)$ & 1.5453 & 0.5701 \\
\hline BAN_AG & $\begin{array}{l}\mathrm{n}^{\mathrm{o}} \text { de banheiros }+0.5 * \text { (lavabos }+ \text { banh. de } \\
\text { empregada })\end{array}$ & 1.1932 & 0.5981 \\
\hline OUT_DEP & $\begin{array}{l}\mathrm{n}^{\mathrm{o}} \text { de áreas externas }+ \text { quintais }+ \text { outros } \\
\text { depósitos }\end{array}$ & 0.6338 & 0.5451 \\
\hline DIST_SE & $\begin{array}{l}\text { distância à Praça da Sé, no centro histórico, } \\
\text { em km }\end{array}$ & 11.81 & 6.19 \\
\hline DIST_BER & $\begin{array}{l}\text { distância ao cruzamento da Av. das Nações } \\
\text { Unidas e Av. Bandeirantes em km }\end{array}$ & 14.20 & 7.18 \\
\hline DIST_CBD & $\begin{array}{l}\text { menor distância entre o centro histórico e o } \\
\text { centro novo em } \mathrm{km}\end{array}$ & 10.452 & 5.924 \\
\hline DUM_SE & dummy: menor distância à Praça da Sé & 0.71 & 0.45 \\
\hline
\end{tabular}

Fonte: elaborado a partir de dados do LUME (2002) e FIPE (1999).

$\mathrm{Na}$ Tabela 3, observamos algumas estatísticas descritivas sobre as características estruturais dos imóveis e as variáveis de distância calculadas entre cada domicílio e os centros de negócios eleitos. Os dados da Fipe (1999) não esgotam todo o escopo de variáveis estruturais. Particularmente faltam duas informações bastante usuais nos estudos hedônicos: a idade do imóvel e a qualidade do acabamento. Estas duas variáveis de controle apresentam elevada significância e sinal esperado negativo para a primeira e positivo para a segunda na maioria das pesquisas. Sua ausência, além de diminuir a 
capacidade de explicação do modelo, acarretará um certo grau de viés sobre os parâmetros estimados. Outra variável bastante usual nos trabalhos com modelos hedônicos para habitação é o tamanho em metro quadrado do imóvel. Neste estudo, o número de cômodos funciona como uma aproximação do tamanho do imóvel, embora sob a forte hipótese implícita de que todos os cômodos têm o mesmo padrão.

\subsection{Seleção de Variáveis Ambientais}

A seleção das variáveis ambientais costuma ser bastante arbitrária. Alguns trabalhos vinculam a escolha delas diretamente ao seu objeto de análise. Outros simplesmente as ignoram e limitam-se a estudar o comportamento das variáveis estruturais. Este trabalho, ao contrário, não tem o foco nas variáveis estruturais nem em uma amenidade específica. Temos, então, o problema de decidir o espectro de variáveis ambientais a ser analisado.

Ainda que a seleção seja ad hoc, partimos para um critério um pouco mais intuitivo. Fazendo regredir o valor do aluguel sobre as variáveis de controle da Tabela 3, obteremos um resíduo que incorporará todas as externalidades urbanas e, ainda, algumas variáveis de controle não consideradas. Se aceitarmos este resíduo como proxy dos efeitos ambientais, ainda que estejamos conscientes de que uma parte de sua variância depende de fenômenos não ambientais, poderemos gerar curvas de nível de externalidades urbanas, de negativas a positivas, sobre a cidade.

Iniciamos fazendo regredir o aluguel apenas sobre as variáveis estruturais. ${ }^{13} \mathrm{Com}$ isso, temos um resíduo que basicamente representa o valor da terra. ${ }^{14}$ Excetuando-se alguns trechos, aparentemente viesados sob a influência de pontos isolados, o comportamento das curvas é bastante intuitivo, como mostra o Mapa 4. Na região leste, norte e extremo oeste da cidade, prevalecem externalidades negativas, enquanto na região centro-oeste, considerada a área nobre da cidade, dominam as externalidades positivas.

\footnotetext{
${ }^{13}$ Ver Apêndice, Tabela A1.

${ }^{14}$ Ver Dubin (1992).
} 


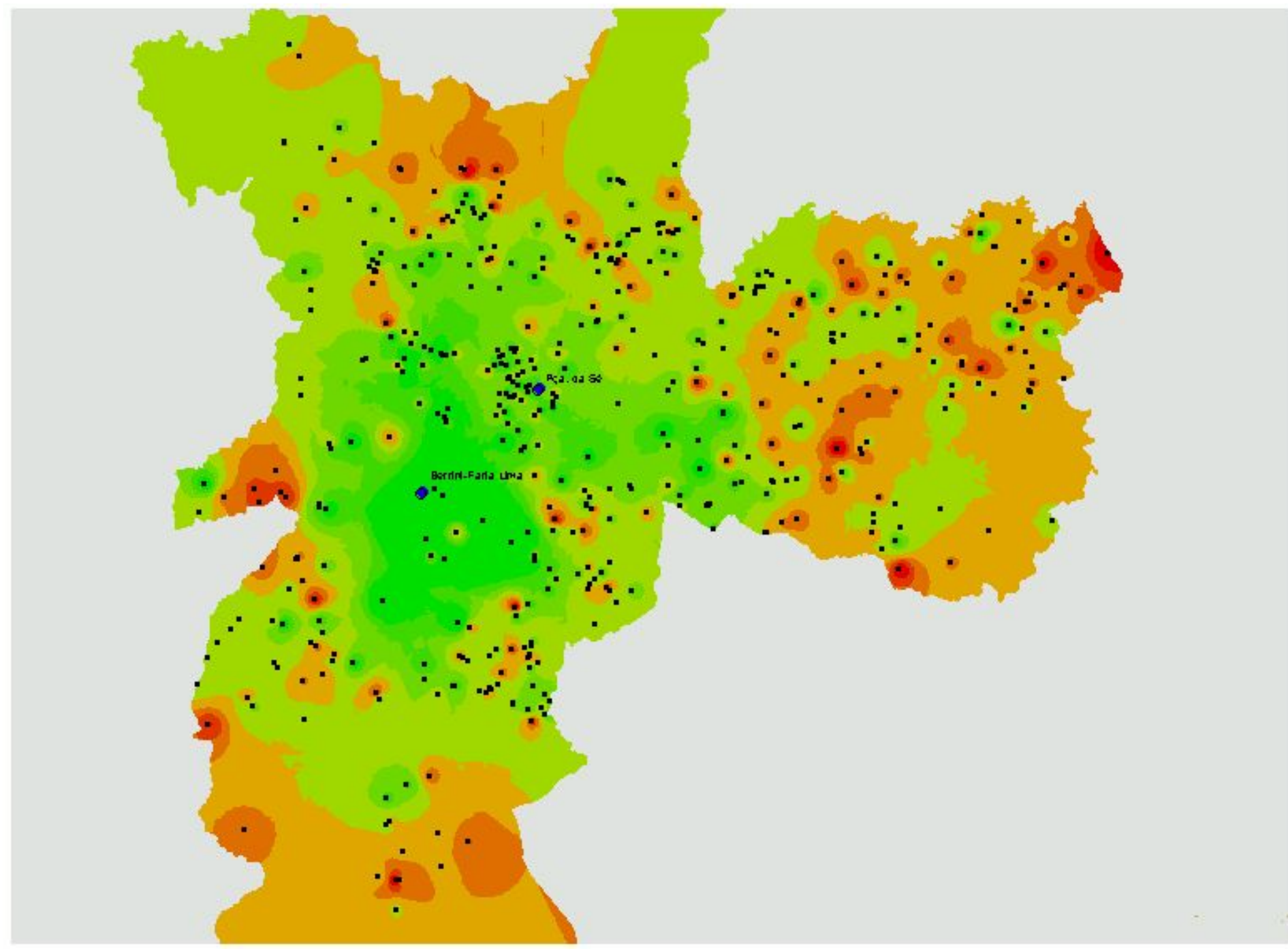

Mapa 4:

Interpolação de Resíduos da

Regressão 1 -

São Paulo

- Domicílios

Peqa.da Se

- Berrini-Faria Lima

Extemalidades Ubanas

$<-3$ Std. Dew.

$-2 \cdots 1$ Std. Dev. -1 - 0 Std. Dev.

Mean

0.1 Std. Dev.

1 - 2 Std. Dev.

2.3 Std. Dev.
$>3$ Std. Dev.

No Data

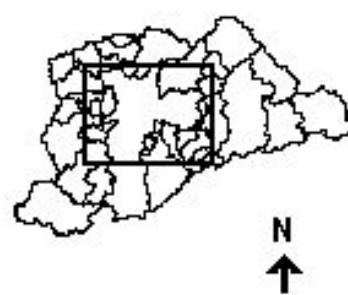

$0 \quad 5$ Kilometers

FONTES:

Eu barada a pa nir de dadas: LU W1E 2002: 
Os picos de gradientes de preços estão muito próximos dos pontos escolhidos como centro de negócios. Isto reforça o papel da proximidade aos locais de trabalho na formação de preços de aluguel. O pico ao redor do complexo Berrini-Faria Lima parece um pouco mais elevado se comparado à Praça da Sé. Essa diferença pode ser resultado das amenidades, já que o centro novo cresceu próximo a regiões de maior poder aquisitivo, enquanto o centro velho, como já falamos, sofre com a degradação provocada pelo excesso de densidade estrutural, trânsito e criminalidade. Voltaremos a este assunto quando incluirmos as variáveis ambientais.

Na segunda regressão adotamos o modelo monocêntrico, incorporando uma variável de distância ao centro velho. ${ }^{15}$ Quando expurgamos o efeito acessibilidade, notamos uma menor diferenciação centro-periferia tanto no sentido leste quanto no sentido sudeste e norte, de acordo com o Mapa 5. A região central agora apresenta resíduos num patamar negativo. A região sudoeste continua fortemente influenciada pelas amenidades positivas, enquanto as regiões ao extremo leste e sul passam a revelar sinais positivos. Isso talvez seja um efeito indesejado da introdução de uma variável de distância linear ao centro. A periferia talvez esteja sendo compensada excessivamente.

Nos Mapas 6 e 7, apresentamos os resíduos para o caso duocêntrico com duas distâncias e com distância mínima. ${ }^{16}$ Diferente do acontecido com a região central, ao expurgarmos o efeito distância ao complexo Berrini-Faria Lima, a região no entorno e no próprio centro novo permanece com valores bastante positivos. Isso confirma que o pico de gradiente no centro novo deve-se, em parte, à boa qualidade da zona residencial próxima.

\footnotetext{
${ }^{15}$ Ver Apêndice, Tabela A1

16 Idem.
} 


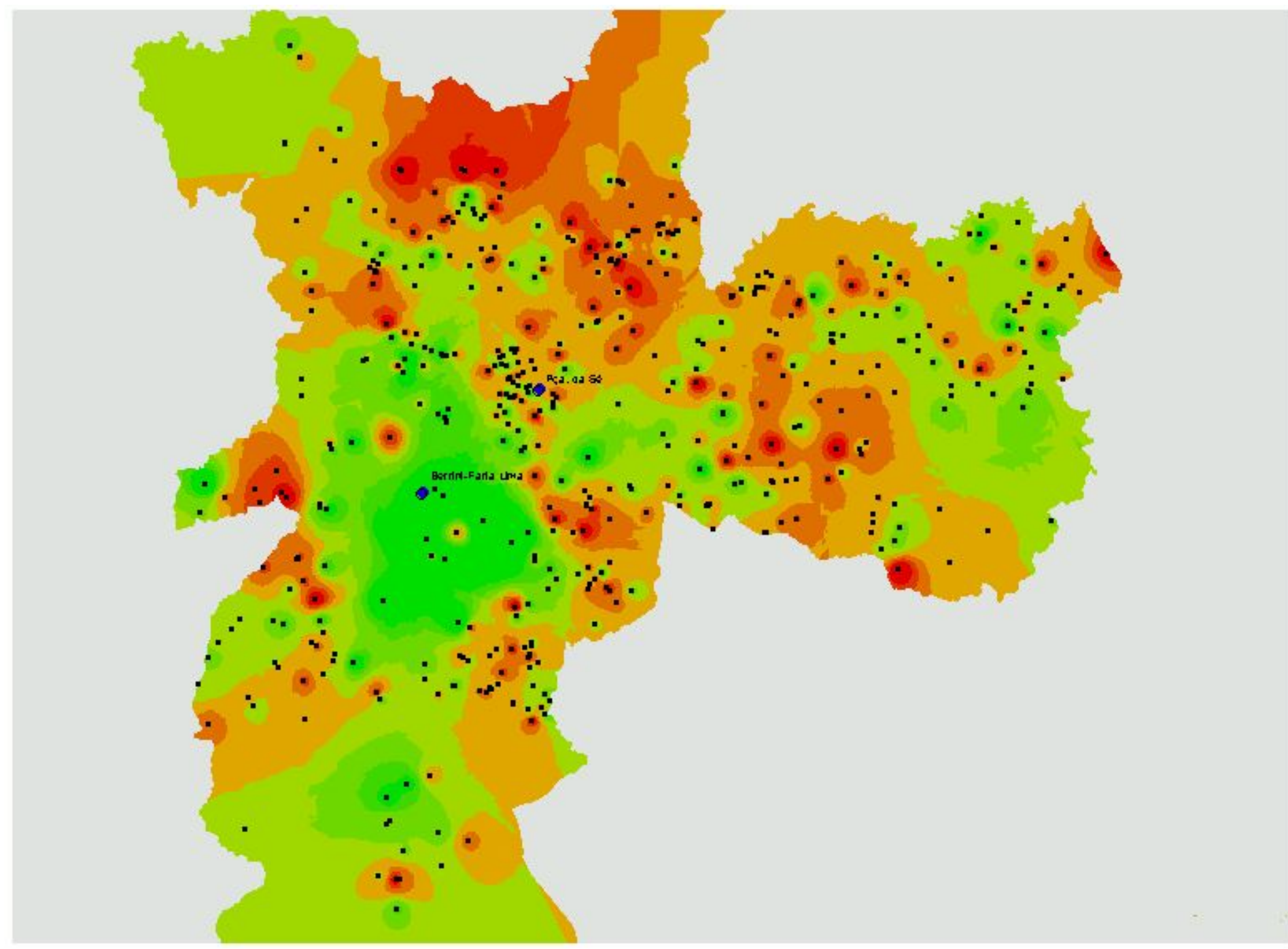

Mapa 5:

Interpolação de Resíduos da

Regressão 2 -

São Paulo

- Domicílios

Peqa.da Se

- Berrini-Faria Lima

Extemalidades Ubanas

$<-3$ Std. Dew.

$-2 \ldots 1$ Std. Dev. -1 - 0 Std. Dev.

Mean

0.1 Std. Dev.

$1-2$ Std. Dev.
2.3 Std. Dev.

> 3 Std. Dev.

No Data

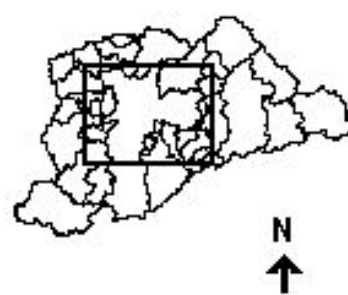

$0 \quad 5$ Kilometers

FONTES:

Eu barada a pa nir de dadas: LU W1E 2002: 


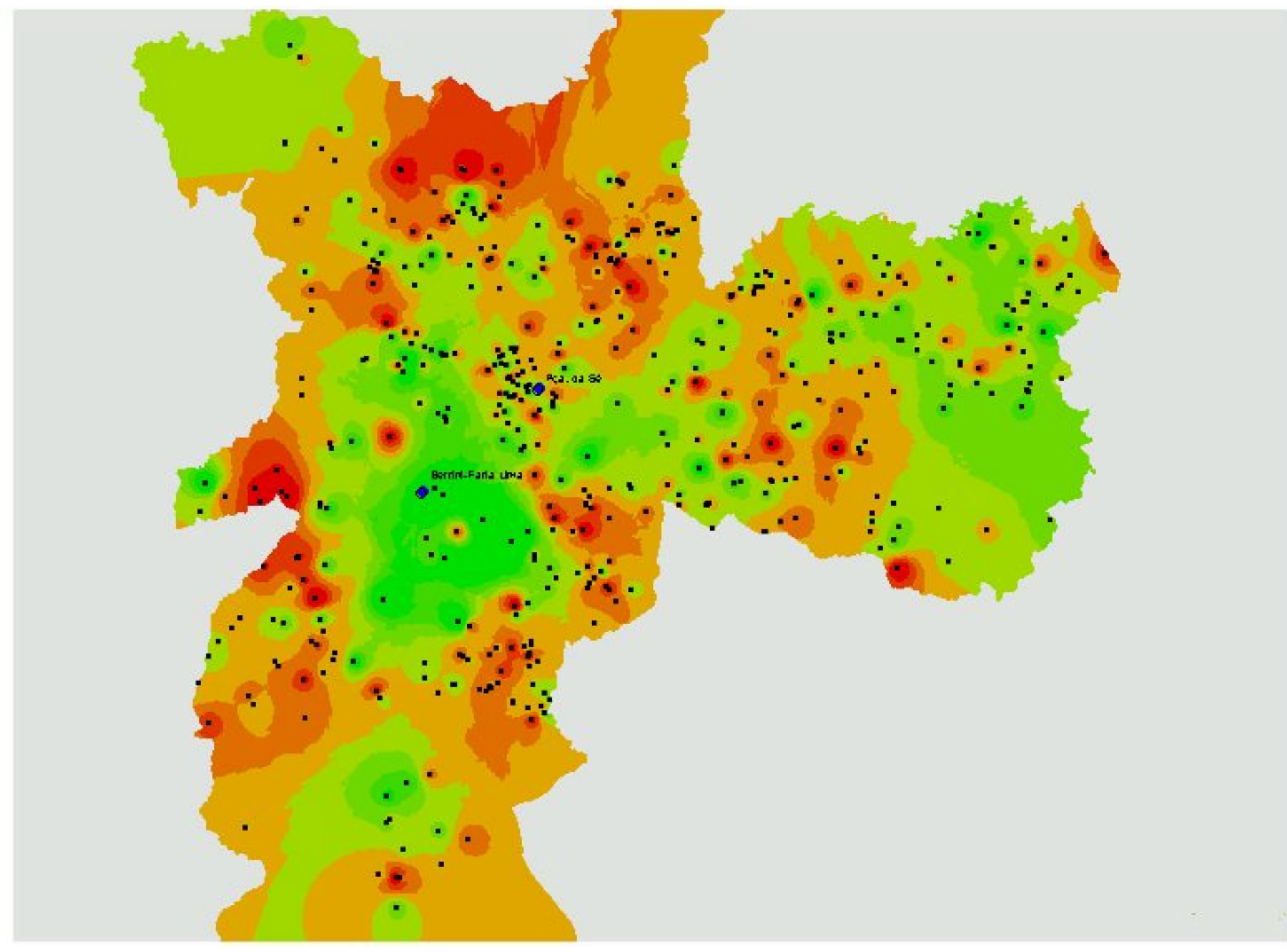

\section{Mapa 6:}

Interpolação de Resíduos da

Regressão 3 -

São Paulo
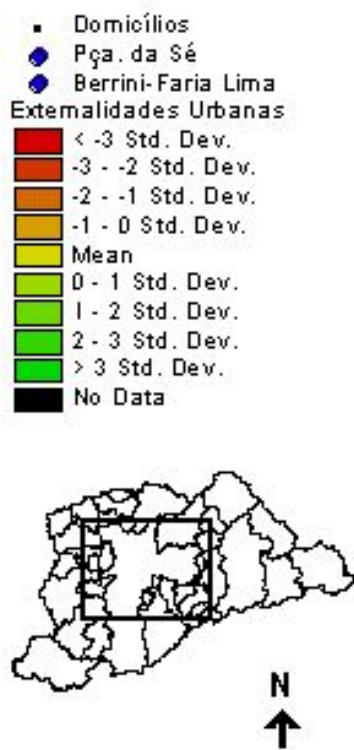

5 Kilometers

FONTES:

Eu barada a pa nir de dadas: UU U너 2002: 


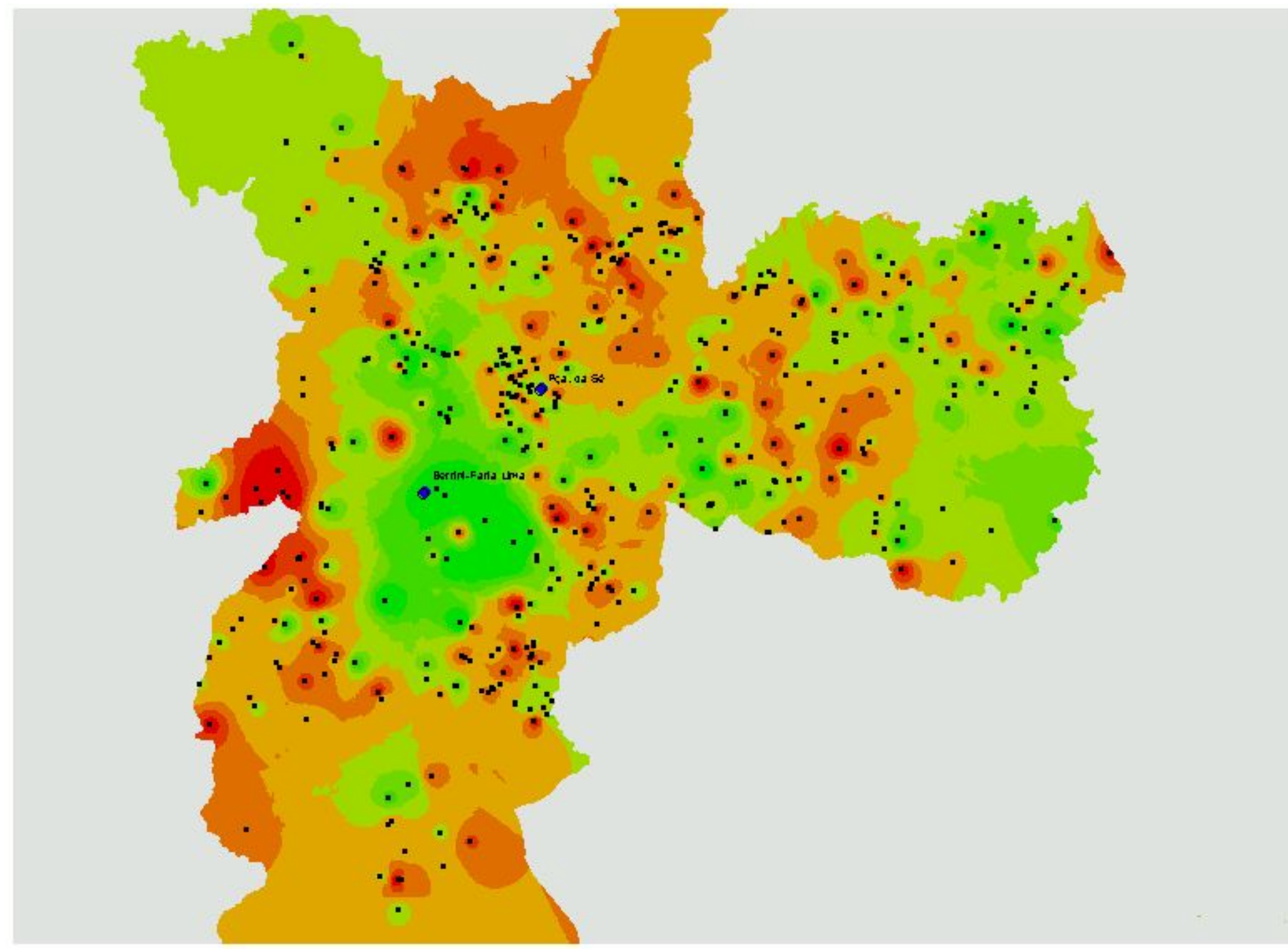

\section{Mapa 7:}

Interpolação de Resíduos da

Regressão 4 -

São Paulo
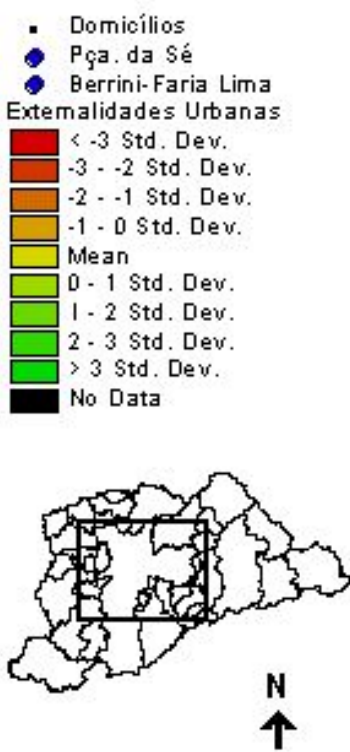

5 Kilometers

FONTES:

Eu barada a pa nir de dadas: UU U너 2002: 
O vetor de acessibilidade com duas distâncias acentua o efeito de compensação na vizinhança. Isso é um pouco amenizado quando utilizamos apenas a distância mínima. Por outro lado, regiões relativamente mais próximas ao centro novo, como oeste, sudoeste e sudeste, passam a revelar resíduos mais negativos. No caso das duas últimas regiões, a pesquisa confirma resultados esperados, entretanto, com relação à zona oeste, acreditamos que algumas observações podem não estar correspondendo à média dos distritos. Para amostras maiores, distorções locais como esta seriam compensadas pelas demais observações e poderíamos ter maior confiança nos resultados apresentados. Mais que isso, poderíamos assumir resultados inesperados como reveladores. Entretanto, a amostra da POF/Fipe é representativa apenas do município como um todo. Assim, preferimos encarar com reservas resultados para os distritos.

Entretanto, os resultados obtidos através dos mapas de resíduos, em geral, ratificam os fenômenos esperados e servem de indicadores para a seleção de variáveis ambientais. Para cada região procuramos encontrar a explicação adequada para o tipo de ocorrência. $\mathrm{Na}$ região extremo leste, norte e sul, acreditamos que parte do efeito negativo seja explicado pela violência e pelas condições precárias de moradia, como a presença de favelas; na região centro-oeste, alguns prováveis motivos de valorização devem ser, além da menor ocorrência de violência e de condições precárias de moradia, a concentração de áreas verdes. Para o centro histórico da cidade gostaríamos de testar o efeito saturação, entretanto não encontramos uma proxy satisfatória. O problema do trânsito poderia ser uma indicação, mas não havia uma medida que pudesse ser estendida para toda a cidade. A verticalidade das construções ou a densidade estrutural, por definição, seria a melhor variável para captar o uso excessivo do solo. Entretanto, enfrentaríamos o problema de endogeneidade, já que o preço da terra condiciona o tipo de construção, pois zonas mais valorizadas tendem a ser mais verticalizadas. ${ }^{17}$

Além disso, incorporamos um conjunto de variáveis geralmente presentes nos estudos de preços hedônicos para habitação: uso do solo para fins comerciais e industriais, transporte público e poluição atmosférica. Resolvemos ainda incluir o zoneamento urbano. A política de zoneamento constantemente é alvo dos rent-seekers, terminologia econômica para os caçadores de renda, aqueles que conseguem auferir renda por

\footnotetext{
${ }^{17}$ Ver Brueckner (1987).
} 
mecanismo de pressão aos órgãos públicos. Na tabela 4, estão listadas as variáveis ambientais selecionadas. ${ }^{18}$

Tabela 4: Variáveis Ambientais

\begin{tabular}{|c|c|c|c|}
\hline Variável & Descrição & Média & Dv-padrão \\
\hline DIST_METR & $\begin{array}{l}\text { distância à estação de metrô mais próxima } \\
\text { em km }\end{array}$ & 3.84 & 3.27 \\
\hline DIST_TREM & $\begin{array}{l}\text { distância à estação de trem mais próxima em } \\
\mathrm{km}\end{array}$ & 3.00 & 1.81 \\
\hline TCONST_C & $\begin{array}{l}\text { área construída comercial sobre área } \\
\text { construída total }(* 100) \text { por distrito }\end{array}$ & 17.17 & 10.01 \\
\hline TCONST_I & $\begin{array}{l}\text { área construída industrial sobre área } \\
\text { construída total }(* 100) \text { por distrito }\end{array}$ & 5.58 & 4.78 \\
\hline PART_IN & $\begin{array}{l}\text { partículas inaláveis em } \mu \mathrm{g} / \mathrm{m}^{3} \text { de acordo com } \\
\text { estação medidora mais próxima }\end{array}$ & 47.08 & 5.40 \\
\hline COEF_ARB & $\begin{array}{l}\text { área arbórea sobre área urbana }(* 100) \text { por } \\
\text { distrito }\end{array}$ & 6.21 & 5.25 \\
\hline CRIME & taxa de homicídios por 100.000 habitantes & 54.87 & 25.81 \\
\hline POP_FAV & $\begin{array}{l}\text { população favelada sobre pop. total }(* 100) \\
\text { por distrito }\end{array}$ & 6.39 & 7.17 \\
\hline Z_ER & zona estritamente residencial & 0.0121 & 0.1093 \\
\hline Z_RB & $\begin{array}{l}\text { zona residencial de densidade demográfica } \\
\text { baixa }\end{array}$ & 0.7465 & 0.4355 \\
\hline Z_RM & $\begin{array}{l}\text { zona residencial de densidade demográfica } \\
\text { média }\end{array}$ & 0.1408 & 0.3482 \\
\hline Z_M & zona mista & 0.0805 & 0.2723 \\
\hline Z_I & zona industrial & 0.0060 & 0.0775 \\
\hline Z_E & zonas especiais & 0.0141 & 0.1180 \\
\hline
\end{tabular}

Fonte: elaborado a partir de dados do LUME (2002), SEADE (2000), CETESB (1999) e SVMA (1994).

Todas as variáveis ambientais têm relação direta com o espaço e com a qualidade do bairro. Entretanto, em muitos estudos de preços hedônicos para habitação, os autores

${ }^{18}$ Ver Apêndice, Mapas A1, A2, A3, A4 e A5. 
confundem qualidade da vizinhança com o nível sócio-econômico das pessoas que moram nessa mesma vizinhança. Assim, é comum a inclusão de variáveis sócioeconômicas, como renda, educação e saúde. Acreditamos que, se o bairro é bom, então o preço médio dos aluguéis será elevado e, assim, apenas os indivíduos de maior poder aquisitivo poderão escolher esse local para moradia. Portanto, preço do aluguel explica renda, ou seja, novamente há um problema de endogeneidade. Ademais, como esperamos que as variáveis sócio-econômicas, como renda, estejam altamente correlacionadas com a presença de amenidades, sua inclusão torna difícil a estimação dos parâmetros ambientais. ${ }^{19}$

Entretanto, acreditamos que, de fato, algum efeito sócio-econômico influencia a escolha residencial das famílias. O "status social" de um bairro é um bom exemplo disso. Estratégias de marketing, além de evidenciarem a qualidade ambiental dos empreendimentos, por causa de sua localização, costumam destacar o fato de eles se situarem em regiões emergentes. De qualquer maneira, considerando o que foi exposto, optamos por incluir apenas as variáveis estritamente ambientais ao modelo.

\footnotetext{
${ }^{19}$ Ver Apêndice Tabela A2.
} 


\section{Resultados}

Inicialmente, aplicamos o modelo para estimar o preço hedônico marginal das variáveis ambientais originais, de acordo com a equação (12). Foram testadas as três opções de vetores de acessibilidade: monocêntrico; duocêntrico(a), que inclui duas variáveis de distância; e duocêntrico(b), que considera apenas a distância mínima e uma dummy demonstrando a que centro se refere. Em seguida, selecionamos as variáveis ambientais mais significativas e construímos fatores, resumindo essa informação. Esses fatores, então, foram utilizados numa segunda rodada de estimações, como exposto na equação (15), novamente para os três casos de acessibilidade. Por último, investigamos a presença de dependência espacial no modelo.

\section{Tabela 5: Regressão Linear sobre Variáveis Ambientais}

\begin{tabular}{lrrrrrr}
\hline & \multicolumn{2}{c}{ Monocêntrico } & \multicolumn{2}{c}{ Duocêntrico.a } & \multicolumn{2}{c}{ Duocêntrico.b } \\
\hline & \multicolumn{1}{c}{ coef. } & prob. & coef. & prob. & \multicolumn{1}{c}{ coef. } & \multicolumn{1}{c}{ prob. } \\
\hline C & 114.676 & 0.0492 & 156.866 & 0.0082 & 181.074 & 0.0046 \\
SALA & 71.0099 & 0.0000 & 71.0431 & 0.0000 & 71.4649 & 0.0000 \\
GARAG & 32.4128 & 0.0105 & 33.0117 & 0.0085 & 33.5320 & 0.0077 \\
DORM_AG & 68.5297 & 0.0000 & 67.4612 & 0.0000 & 68.2021 & 0.0000 \\
COZ_AG & 39.1733 & 0.0003 & 39.2764 & 0.0002 & 38.2536 & 0.0004 \\
BAN_AG & 77.8238 & 0.0000 & 76.5457 & 0.0000 & 77.3382 & 0.0000 \\
OUT_DEP & -14.7701 & 0.1689 & -12.9842 & 0.2226 & -14.6740 & 0.1693 \\
DIST_SE & -7.1298 & 0.0000 & -0.0073 & 0.9978 & & \\
DIST_BER & & & -6.9341 & 0.0014 & & \\
DIST_CBD & & & & & -7.2613 & 0.0000 \\
DUM_SE & & & & & -33.7772 & 0.1095 \\
DIST_MET & 2.4165 & 0.2957 & 0.4349 & 0.8543 & 2.0125 & 0.3755 \\
DIST_TRE & -6.2551 & 0.0720 & -5.5220 & 0.1093 & -5.4355 & 0.1055 \\
TCONST_C & 0.6449 & 0.4328 & 0.3171 & 0.6991 & 0.2034 & 0.8071 \\
TCONST_I & -1.4735 & 0.2350 & -1.8638 & 0.1293 & -1.6918 & 0.1677 \\
PART_IN & 0.8027 & 0.4515 & 1.2501 & 0.2407 & 0.7128 & 0.4987 \\
COEF_ARB & 4.4152 & 0.0001 & 0.1455 & 0.9335 & 0.5912 & 0.7222 \\
CRIME & -0.9983 & 0.0068 & -0.9665 & 0.0082 & -1.0670 & 0.0030 \\
POP_FAV & 0.1100 & 0.9295 & -1.3242 & 0.3122 & -1.3503 & 0.3052 \\
Z_ER & 354.010 & 0.0000 & 343.342 & 0.0000 & 338.855 & 0.0000 \\
Z_RM & 1.2518 & 0.9443 & 0.8265 & 0.9628 & 2.0784 & 0.9066 \\
Z_M & 2.8441 & 0.9080 & 4.9350 & 0.8395 & 4.8928 & 0.8408 \\
Z_I & -11.4153 & 0.8708 & 1.0192 & 0.9883 & 2.8386 & 0.9676 \\
Z_E & -4.8121 & 0.9193 & -6.4959 & 0.8901 & -10.4534 & 0.8244 \\
\hline R 2 adj & 0.6816 & & 0.6878 & & 0.6858 & \\
\hline \hline
\end{tabular}


A primeira rodada de regressões revela que as variáveis estruturais são para todos os casos bastante significativas. Como optamos pela função linear, os coeficientes revelam preços constantes. Assim, cada sala aumenta o valor do aluguel em aproximadamente $\mathrm{R} \$ 71,00$, cada garagem em $\mathrm{R} \$ 33,00$, cada dormitório em $\mathrm{R} \$ 68,00$, e assim sucessivamente. Lembramos que os valores refletem o mercado em 1998, antes da ruptura cambial e da retomada da inflação, que impactaram os preços dos aluguéis nos últimos anos.

Considerando a configuração monocêntrica, observamos que o modelo se encaixa de acordo com o retratado na teoria. A região central apresenta coeficiente negativo e significativo, formando, assim, o gradiente de preços declinante em direção à periferia. Sob essa hipótese, o modelo revela apenas algumas variáveis ambientais significativas: distância às estações de trem (significativa a 10\%), coeficiente arbóreo, crime e zona estritamente residencial.

Em grande parte dos estudos hedônicos para habitação, o impacto dos transportes públicos é pouco significativo. De acordo com Bowes e Ihlanfeldt (2001), esse resultado decepcionante revela, na verdade, o efeito ambíguo do fenômeno. As estações de trem e metrô podem estar contribuindo, simultaneamente, de forma positiva e negativa para a vizinhança. Uma estação beneficia a redondeza pelo aspecto de acessibilidade e fomento de atividades de comércio varejista. Por outro lado, aumenta a incidência de criminalidade e provoca na região adjacente mais distúrbios, como a poluição sonora. Biderman (2001) encontra resultados para a região metropolitana de São Paulo que destacam esse efeito diferenciado do metrô sobre as regiões adjacentes e as regiões mais afastadas. Os efeitos negativos tendem a prevalecer num raio próximo à estação, e os efeitos positivos passam a dominar a partir dessa fronteira. Neste trabalho, os resultados obtidos para estações de trem destacam seu benefício. Com relação às estações de metrô, acreditamos que a baixa significância e o sinal positivo para a distância podem estar revelando a ausência de informações ambientais adequadas para a região central. Como as linhas de metrô concentram-se no centro da cidade, é possível que a variável esteja captando outros efeitos não considerados sobre a região.

As taxas de construção comercial e industrial, embora os coeficientes apareçam com sinal esperado, não apresentam significância. No caso do comércio, a provável elevada 
correlação com distância à região central pode estar elevando a variância do parâmetro estimado. No caso da indústria, existe uma forte autocorrelação com a linha férrea. ${ }^{20}$ Podemos insistir nessas amenidades quando da construção dos fatores.

No caso da poluição, de fato a regressão não revela nenhuma significância possível. A principal razão para isso reside no fato de que existe pouca variância intra-urbana de partículas inaláveis. Portanto, a variável é praticamente uma constante.

A melhor estimativa de qualidade ambiental parece ser o coeficiente arbóreo. O coeficiente é positivo, cada ponto percentual a mais de área verde sobre área urbana aumenta o aluguel aproximadamente em $\mathrm{R} \$ 4,50$, e significante $1 \%$. Se observarmos o Mapa A3, no Apêndice, a região mais nobre da cidade, a região centro-oeste, apresenta um dos mais elevados coeficientes arbóreos, acompanhada pela região sudeste e pela região sul, onde é definida a Área de Proteção aos Mananciais.

A criminalidade também aparece como um elemento decisivo na formação de preços para o mercado de aluguéis no Município de São Paulo. Os índices de violência na cidade afetam principalmente a periferia: regiões norte, leste e sudeste. Concomitantemente, a incidência de favelas ocorre preponderantemente nas mesmas regiões, mas, neste caso, a variável não apresenta significância. ${ }^{21} \mathrm{~A}$ elevada correlação entre a presença de favelas e criminalidade deve estar prejudicando a estimação dos coeficientes.

Quanto às dummies de zoneamento, o único resultado significante foi a circunscrição de zonas estritamente residenciais (ZER). Esta parece ser a melhor proxy para o que chamamos de aprazibilidade. As ZER são pequenas glebas de padrão de construção horizontal inseridas nos distritos que resguardam a tranqüilidade dos moradores. Entretanto, acreditamos que o seu valor, R\$ 354,00 aproximadamente, dado os R\$ 353,20 de média dos aluguéis para toda a amostra, esteja superestimado. As ZER abrigam geralmente as residências de famílias mais abastadas, devendo estar, portanto, captando o efeito de variáveis omitidas, como, por exemplo, a qualidade de acabamento das construções.

\footnotetext{
${ }^{20}$ Ver Mapas A1 e A4.

${ }^{21}$ Ver Mapa A5.
} 
A inclusão de uma variável de distância ao centro novo, no modelo duocêntrico(a), altera pouco o quadro das estimativas, e o ajuste do modelo tem uma melhora desprezível: passa de 0.6816 para 0.6878 . Entretanto valem algumas observações. A distância ao centro histórico perde sua significância, e todo efeito acessibilidade passa a ser dirigido ao centro novo. A taxa de construção industrial passa a ser quase significante a $10 \%$, mas, por outro lado, o coeficiente arbóreo perde sua importância. Como havíamos discutido, os pontos de referência eleitos para distâncias podem estar representando picos de gradientes de preços que não necessariamente expressam acessibilidade. No caso, o centro novo, que se desenvolveu no interior do cluster de regiões privilegiadas da cidade, pode estar expressando, paralelamente ao efeito acessibilidade, a qualidade ambiental de seu entorno e, assim, extraindo resultados que deveriam ser captados pelo vetor ambiental.

Para o modelo duocêntrico(b), com uma variável de distância, os resultados permanecem estáveis. As variáveis estruturais e ambientais mantêm aproximados os valores dos coeficientes. O ajuste do modelo também pouco se altera, caindo para 0.6858. O gradiente de preços, representado pela variável DIST_CBD, é negativo e significativo, mas a dummy para a região central não se revela importante.

Nossa segunda opção foi fazer regredir o valor do aluguel sobre fatores que condensariam as informações presentes nas variáveis ambientais. A vantagem deste procedimento é escapar da multicolinearidade que aumenta a variância dos parâmetros e reduz sua significância. A desvantagem é que os fatores nem sempre apresentam algum significado econômico intuitivo a Assim, corremos o risco de estar estimando o preço de algo pouco compreensível. Para facilitar esta tarefa, primeiro optamos pela rotação varimax, que maximiza a variância de cada variável num mesmo fator e por transformar todas as variáveis com conotação negativa - as "desamenidades" - no seu inverso. Feitas algumas combinações, conseguimos construir fatores relativamente compreensíveis, como mostra a Tabela $6 .{ }^{22}$

\footnotetext{
${ }^{22}$ Resultados adicionais da construção dos fatores encontram-se na Tabela A3.
} 
A terminação INV indica o inverso de uma variável. Assim, temos o inverso da distância às estações de metrô, o inverso às estações de trem, o inverso da taxa de construção industrial e o inverso do crime. Taxa de construção industrial, coeficiente arbóreo e zona estritamente residencial permanecem como estavam.

Tabela 6: Matriz de Cargas Fatoriais Rotacionadas

\begin{tabular}{lrrr}
\hline & \multicolumn{3}{c}{ Fatores } \\
\hline & 1 & 2 & 3 \\
\hline MET_INV & 0.458 & -0.058 & 0.103 \\
TRE_INV & 0.021 & 0.006 & -0.056 \\
IND_INV & 0.853 & 0.033 & -0.088 \\
TCONST_C & 0.758 & -0.026 & -0.069 \\
COEF_ARB & -0.177 & 0.978 & -0.114 \\
CRI_INV & 0.367 & 0.213 & 0.905 \\
Z_ER & 0.011 & 0.119 & 0.023 \\
\hline \hline
\end{tabular}

O inverso de criminalidade aparece razoavelmente representado em todos os fatores, entretanto sua incidência é preponderante, e praticamente exclusiva, no Fator 3. Assim, "batizamos" o terceiro fator de "segurança". O Fator 1 concentra as variâncias do inverso da distância ao metrô, do inverso da presença de atividade industrial e da presença de atividade comercial. Portanto, é um fator associado à proximidade da região mais urbanizada, à presença de infraestrutura. Chamamos esse fator, então, de "infraestrutura". O segundo fator também é bastante evidente. Praticamente toda a variância é motivada pela presença de áreas verdes, restando um pouco para ZER. Denominamo-lo, então, de "aprazibilidade".

Rodando a regressão com os fatores para os três casos de acessibilidade, chegamos aos resultados expostos na Tabela 7. Observamos, primeiramente, que os preços marginais das variáveis estruturais permanecem estáveis. É interessante notar que a ausência de amenidades primárias eleva a significância da constante, que agora possui um valor inferior, caindo de R\$ 150,00 para $\mathrm{R} \$ 100,00$ na média. Como dissemos, a exígua diferença intra-urbana de poluentes torna PART_IN praticamente uma segunda constante, perturbando a variância do coeficiente da constante original. 
Tabela 7: Regressão Linear sobre Fatores

\begin{tabular}{lcccccc}
\hline & \multicolumn{2}{c}{ Monocêntrico } & \multicolumn{2}{c}{ Duocêntrico.a } & \multicolumn{2}{c}{ Duocêntrico.b } \\
\hline & coef. & prob. & coef. & prob. & coef. & \multicolumn{1}{c}{ prob. } \\
\hline C & 85.0424 & 0.0007 & 102.448 & 0.0001 & 108.244 & 0.0001 \\
SALA & 78.2854 & 0.0000 & 79.8526 & 0.0000 & 80.1177 & 0.0000 \\
GARAG & 33.4091 & 0.0010 & 32.7800 & 0.0109 & 34.3425 & 0.0077 \\
DORM_AG & 75.6848 & 0.0000 & 73.6109 & 0.0000 & 74.1721 & 0.0000 \\
COZ_AG & 35.4688 & 0.0013 & 35.4914 & 0.0012 & 34.6267 & 0.0015 \\
BAN_AG & 82.3986 & 0.0000 & 82.4077 & 0.0000 & 82.0941 & 0.0000 \\
OUT_DEP & -2.7021 & 0.8050 & -0.9902 & 0.9275 & -1.5819 & 0.8844 \\
DIST_SE & -5.8936 & 0.0000 & -1.0157 & 0.6236 & & \\
DIST_BER & & & -5.1934 & 0.0046 & & \\
DIST_CBD & & & & & -6.0609 & 0.0000 \\
DUM_SE & & & & & -39.0400 & 0.0496 \\
F1 & 18.3058 & 0.0182 & 22.3779 & 0.0043 & 23.5992 & 0.0023 \\
F2 & 26.3504 & 0.0000 & 7.1443 & 0.4157 & 3.9966 & 0.6443 \\
F3 & 26.3834 & 0.0000 & 30.8029 & 0.0000 & 33.9533 & 0.0000 \\
\hline R $^{2}$ adj & 0.6611 & & 0.6660 & & 0.6659 & \\
\hline \hline
\end{tabular}

Para os três casos de acessibilidade, os resultados com fatores acompanham os apresentados na Tabela 5. No modelo monocêntrico, a distância ao centro histórico é negativa e significativa a $1 \%$. Todos os fatores são altamente significativos e, como esperávamos, com valores positivos. "Infra-estrutura" possui um preço marginal de R\$ 18,30, “aprazibilidade”, de R\$26,35 e “segurança”, de R\$26,38.

Para o modelo duocêntrico(a), novamente a distância à Praça da Sé perde significância, enquanto a distância ao Complexo Berrini-Faria Lima mantém-se significativo a 1\%, com sinal negativo. Neste caso, o fator "aprazibilidade", composto essencialmente da variância de coeficiente arbóreo, perde significância, repetindo o caso das variáveis ambientais originais. Os outros fatores permanecem relevantes.

As alterações são quase imperceptíveis para o modelo duocêntrico(b). Apenas os fatores “infra-estrutura" e "segurança" revelam-se significativos - R \$23,60 para o primeiro e R\$ 33,95 para o segundo. A variável de acessibilidade constrói o gradiente de preços decrescente, mas agora a dummy relativa ao centro histórico é significativa a $5 \%$. $\mathrm{O}$ intercepto do centro histórico é R\$39,00 menor. É provável que a perda parcial de informações ambientais tenha sido transferida para o vetor de acessibilidade, configurando, deste modo, a degradação do centro histórico. 
Concluídas as estimações, passamos para os testes de dependência espacial. Utilizamos o teste LM, que exibe isoladamente a necessidade de incorporação de uma variável dependente defasada ou a reespecificação do resíduo. Para os dois casos experimentamos a matriz de defasagens especiais $W$, com o inverso das distâncias e o inverso ao quadrado das distâncias. Os resultados para todas as equações estimadas estão na Tabela 8.

Tabela 8: Análise de Dependência Espacial

\begin{tabular}{|c|c|c|c|c|}
\hline \multirow[t]{2}{*}{ Regressões } & \multicolumn{2}{|c|}{$W: d^{-1}$} & \multicolumn{2}{|c|}{$W: d^{-2}$} \\
\hline & $\begin{array}{c}L M_{e} \\
\text { (prob) }\end{array}$ & $\begin{array}{l}L M_{\text {lag }} \\
\text { (prob) }\end{array}$ & $\begin{array}{c}L M_{e} \\
\text { (prob) }\end{array}$ & $\begin{array}{l}L M_{\text {lag }} \\
\text { (prob) }\end{array}$ \\
\hline (1) $p=\alpha_{0}+\alpha_{1} S$ & 0.0000 & 0.0000 & 0.1700 & 0.3473 \\
\hline (2) $p=\alpha_{0}+\alpha_{1} S+\alpha_{2}$ A(Mono) & 0.0073 & 0.4499 & 0.3410 & 0.7453 \\
\hline (3) $p=\alpha_{0}+\alpha_{1} S+\alpha_{2} A($ Duо.a $)$ & 0.0668 & 0.1768 & 0.3542 & 0.6112 \\
\hline (4) $p=\alpha_{0}+\alpha_{1} S+\alpha_{2} A($ Duo.b) & 0.0332 & 0.0287 & 0.3774 & 0.5860 \\
\hline (5) $p=\alpha_{0}+\alpha_{1} S+\alpha_{2} A($ Mono $)+\alpha_{3} E$ & 0.2332 & 0.7779 & 0.3444 & 0.9700 \\
\hline (6) $p=\alpha_{0}+\alpha_{1} S+\alpha_{2} A\left(\right.$ Duo.a) $+\alpha_{3} E$ & 0.2985 & 0.8699 & 0.3334 & 0.9966 \\
\hline (7) $p=\alpha_{0}+\alpha_{1} S+\alpha_{2} A\left(\right.$ Duo.b) $+\alpha_{3} E$ & 0.0509 & 0.5770 & 0.4050 & 0.9462 \\
\hline (8) $p=\alpha_{0}+\alpha_{1} S+\alpha_{2}$ A(Mono) $+\alpha_{3} F(E)$ & 0.5203 & 0.8338 & 0.5402 & 0.6262 \\
\hline (9) $p=\alpha_{0}+\alpha_{1} S+\alpha_{2} A($ Duo.a $)+\alpha_{3} F(E)$ & 0.5780 & 0.6765 & 0.5098 & 0.5655 \\
\hline (10) $p=\alpha_{0}+\alpha_{1} S+\alpha_{2} A($ Duo.b $)+\alpha_{3} F(E)$ & 0.5047 & 0.3804 & 0.5622 & 0.5346 \\
\hline
\end{tabular}

As regressões para as variáveis ambientais expostas na Tabela 5 estão dispostas nas linhas 5-7, e as regressões com fatores apresentados na Tabela 7 estão dispostas nas linhas 8-10. Em todos os casos, tanto para $W: d^{-1}$ como para $W: d^{-2}$, a reespecificação para um modelo hedônico espacial não se revela necessária. Portanto, os preços marginais estimados anteriormente sustentam-se.

Entretanto, é interessante observar que a dependência espacial do modelo vai regredindo à medida que incluímos informações espacializadas, conforme havíamos adiantado. Por exemplo, o teste de autocorrelação nos resíduos para a matriz do inverso das distâncias $W: d^{-1}$ vai perdendo significância a cada linha de regressões. Na equação1, composta apenas com variáveis explicativas estruturais, o p-value, que é de 0.0000 , vai para 0.0073, com a introdução da distância ao centro histórico, na equação 2. Com a inclusão de mais uma variável de distância, na equação 3, o p-value já é de 0.0668 . Quando introduzimos, então, o vetor de variáveis ambientais, o teste já não é mais significativo: 0,2332 na equação 5 e 0,2985 na equação 6 . Portanto, o problema de dependência 
espacial pode ser minimizado desde que disponibilizemos informações geográficas relevantes para o modelo.

Apresentadas todas as alternativas para a estimação dos preços implícitos das amenidades urbanas para o Município de São Paulo, podemos fazer um exercício de avaliação do impacto de vizinhança sobre o aluguel de um domicílio qualquer. Considerando uma habitação com as características médias da amostra - uma sala, dois dormitórios (DORM_AG), duas cozinhas (COZ_AG) e um banheiro (BAN_AG) -, qual seria o preço do aluguel, levando em conta o equilíbrio de mercado de 1998, para a mesma moradia em diferentes partes da cidade?

Escolhemos os preços estimados para o caso do modelo monocêntrico, pois, embora o diferencial de ajuste do modelo em comparação com os outros seja quase nulo, as estimações de preços implícitos das amenidades, neste caso, apresentam maior significância. Quatro variáveis ambientais são significativas a 10\%: DIST_TREM, COEF_ARB, CRIME e Z_ER. Ainda devemos considerar para o cálculo do aluguel a distância ao centro velho.

Imaginemos o mesmo domicílio localizado em cinco pontos diferentes da cidade: o primeiro situado na região central, no distrito da República; o segundo, na zona leste, no distrito do Tatuapé; o terceiro, na zona norte, no distrito de Brasilândia; o quarto, na região centro-oeste, no distrito do Jardim Paulista; e o último, na região sul, no distrito do Jardim Ângela, como mostra o Mapa 8. 


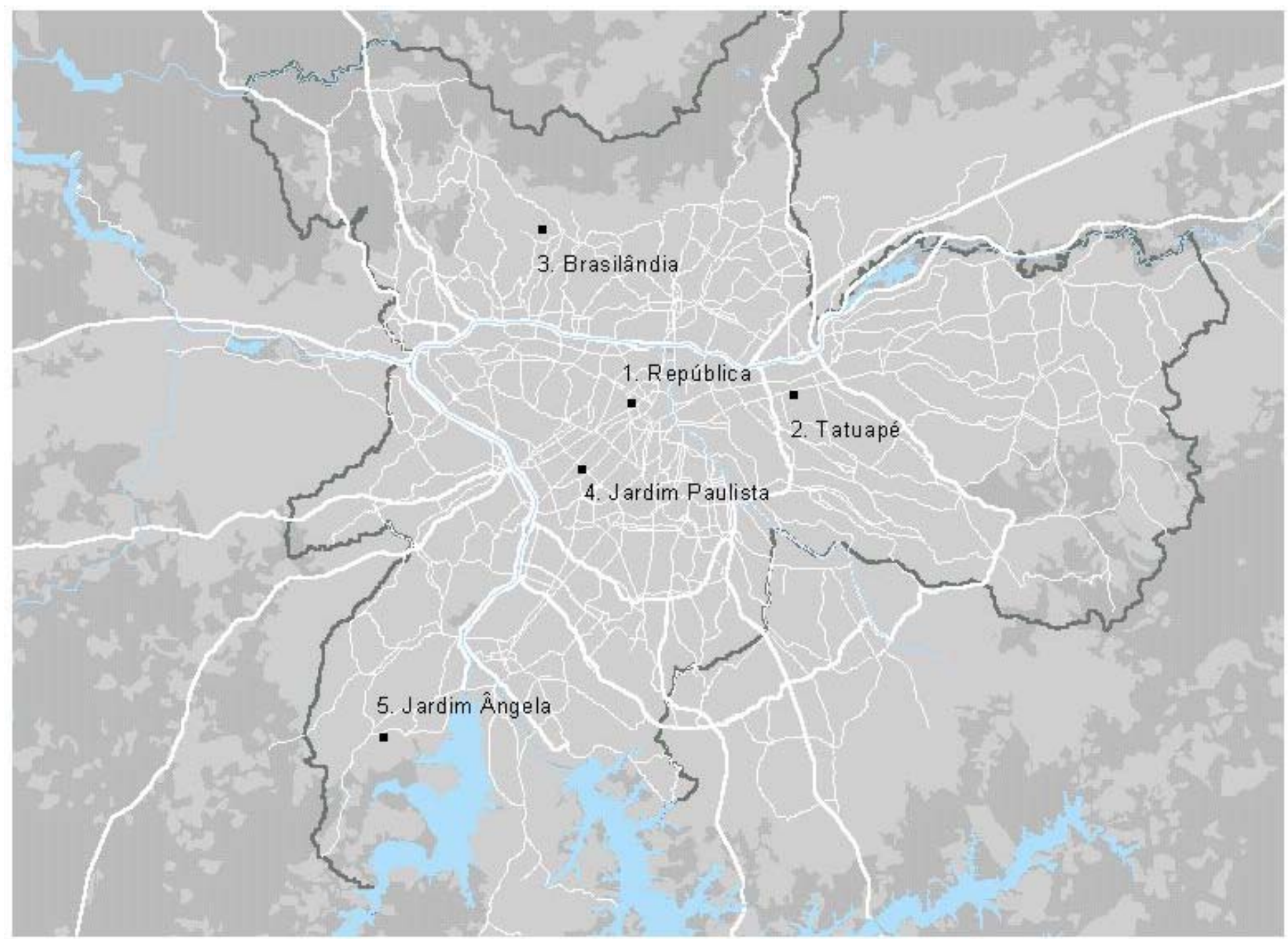

Mapa 8:

Localização de Cinco Domicílios Similares

- Domicílios Rios

Represas

Avenidas

Viário Regional

Limite Municipa

Mancha Urbana

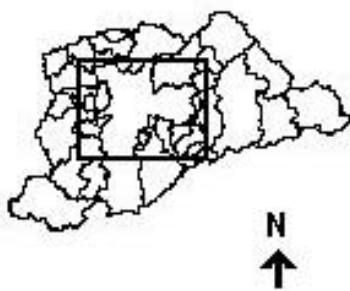

b barada a pa rir de dadas: LU ULE 2002 
Segundo as estimativas de preços para as variáveis habitacionais, o aluguel de cada domicílio vai variar bastante conforme sua localização. Acompanhando os resultados da Tabela 9, observamos que o domicílio situado na República apresenta um aluguel de R\$ 407,82 . Se por um lado tem a vantagem de estar bem próximo ao local de emprego, por outro sofre com a ausência de áreas verdes e os altos índices de violência. O domicílio no Tatuapé apresenta um aluguel bastante próximo do primeiro, R\$ 398,29. A maior distância ao centro de negócios é compensada pela proximidade de uma estação de trem e índices de violência um pouco menores. O aluguel de $\mathrm{R} \$ 292,51$ para a moradia situada em Brasilândia reflete principalmente a distância à Praça da Sé e o elevado grau de violência do distrito, o mesmo acontecendo com o domicílio localizado ao sul da cidade, no Jardim Ângela. Já o domicílio que representa a área nobre da cidade, situado no Jardim Paulista, apresenta um aluguel de R \$ 876,20, motivado principalmente pela presença de áreas verdes, localização em zona estritamente residencial e baixos índices de violência no distrito.

Tabela 9: Aluguel para Cinco Domicílios Similares

\begin{tabular}{l|rrrrr|r}
\hline \multirow{2}{*}{ Distrito } & \multicolumn{5}{|c|}{ Características de Localização } & \multirow{2}{*}{ Aluguel } \\
\cline { 2 - 5 } & DIST_SE & DIST_TREM & COEF_ARB & CRIME & Z_ER & \\
\hline 1 República & 0,892 & 1,602 & 0,52 & 57,11 & 0 & 407,82 \\
2 Tatuapé & 6,905 & 0,812 & 0,59 & 28,99 & 0 & 398,29 \\
3 Brasilândia & 11,569 & 4,549 & 3,78 & 92,31 & 0 & 292,51 \\
4 Jardim Paulista & 4,044 & 2,637 & 21,93 & 8,22 & 1 & 876,20 \\
5 Jardim Ângela & 20,664 & 3,915 & 11,97 & 116,23 & 0 & 243,91 \\
\hline \hline
\end{tabular}

Evidentemente os cinco pontos selecionados não representam todas as nuanças da cidade. $\mathrm{O}$ extremo leste do município, por exemplo, também apresenta padrões como das zonas norte e sul. ${ }^{23}$ Além disso, cada zona da cidade é heterogênea o suficiente para abrigar casos dos mais variados. Contudo, o exercício serve para retratar que, apesar das dificuldades enfrentadas para revelar o preço implícito de amenidades, as estimações realizadas para o Município de São Paulo conseguem retratar com fidelidade as vantagens comparativas de cada região.

\footnotetext{
${ }^{23}$ Isso pode ser observado na Tabela A4.
} 


\section{Considerações Finais}

Para estimar os preços implícitos das amenidades urbanas para a cidade de São Paulo, enfrentamos o dilema de aceitar a baixa significância dos parâmetros na regressão sobre o vetor de variáveis ambientais iniciais, ou construir fatores que corrigiriam a nãoortogonalidade das variáveis e, portanto, melhorariam a sua significância, mas gerariam resultados de menor intuição econômica.

No primeiro caso, foi possível revelar que a presença de estações de trem, áreas verdes e zonas estritamente residenciais contribuem para a elevação do aluguel, enquanto a criminalidade reduz o seu valor. A baixa significância das estações de metrô e da atividade comercial pode ser duplamente explicada pela forte multicolinearidade das variáveis que compõem o vetor e pelo próprio efeito ambíguo dos fenômenos, que contribuem ao mesmo tempo positiva e negativamente para a valorização dos imóveis. Por outro lado, a poluição definitivamente não parece influir na formação de preços. $\mathrm{O}$ mesmo não se pode concluir da presença de favelas, dado que existe uma forte autocorrelação entre esta e criminalidade.

O modelo com fatores, além de repetir qualitativamente os resultados apresentados anteriormente, revela a implicação da oferta de infra-estrutura urbana sobre a moradia. Neste caso, podemos concluir que, de fato, regiões mais centralizadas, servidas de comércio, serviços e transporte público, apresentam valores proporcionalmente mais elevados.

A construção de curvas de nível baseadas nos resíduos da regressão sobre variáveis de controle ajudou na seleção das variáveis explicativas. Este método pode contribuir para pesquisas com modelos hedônicos para habitação, bem como para um conjunto de outros estudos espaciais. Sua utilização deve ser acompanhada por um conjunto de cartas temáticas sobre a região de estudo para que se possa extrair alguma informação relevante sobre o fenômeno.

Entretanto, nem sempre as variáveis desejadas estão disponíveis. Algumas variáveis de controle estão ausentes, como a idade do imóvel e a qualidade de acabamento. Entre as 
variáveis ambientais, não encontramos uma proxy adequada para saturação urbana, como trânsito e densidade estrutural. Existe ainda o problema da escala selecionada. No caso, a maioria das informações está disposta por distrito, o que provavelmente não revela a verdadeira percepção de vizinhança de cada observação.

Quanto aos problemas econométricos levantados: sobre o problema de especificação, resolvemos por simplicidade assumir um modelo linear; o efeito de multicolinearidade foi resolvido com a construção de fatores; e a possibilidade de dependência espacial foi testada. Apenas omitimos a análise de heterocedasticidade espacial. Entretanto, seus efeitos restringem-se à confiabilidade do nível de significância dos parâmetros, sem impor nenhum viés sobre as estimativas. 


\section{Bibliografia}

ALONSO, W. (1964). Locational and Land Use. Cambridge: Harvard University Press.

ANDERSSON, D. E. (1997). Hedonic Prices and Center Accessibility: Conceptual Foundations and an Empirical Hedonic Study of the Market for Condominium Housing in Singapore. Taipei: National Taiwan University.

ANSELIN, L. (1988). Spatial Econometrics: Methods and Models. Dordrecht, Kluwer Academic Publishers.

BARTIK, T.; SMITH, K. (1987). "Urban Amenities and Public Policy”. Handbook of Regional and Urban Economics, v. 2: 1207-1254.

BENSON, E. D.; HANSEN, J. L., SCHWARTZ, A. L. Jr; SMERSH, G. T. (1998). "Pricing Residential amenities: The Value of a View". Journal of Real State Finance and Economics, 16:1, 55-73.

BIDERMAN, C. (2001). Forças de Atração e Expulsão na Grande São Paulo. São Paulo: Fundação Getúlio Vargas.

BOWEN, W. M.; MIKELBANK, B. A.; PRESTEGAARD, D. M. (2001). “Theoretical and Empirical Considerations Regarding Space in Hedonic Housing Price Model Applications”. Growth and Change. v. 32, n. 4 (Fall 2001): 466-490.

BOWES, D. R.; IHLANFELDT, K. R. (2001). "Identifying the Impacts of Rail Transit Stations on Residential Property Values”. Journal of Urban Economics, 50: 125.

BRUECKNER, J. (1987). “The Structure of Urban Equilibria: a Unified Treatment of the Muth-Mills Model". Handbook of Regional and Urban Economics. v. 2: 821-845.

CAN, A. (1990). "The Measurement of Neighborhood Dynamics in Urban House Prices”. Economic Geography, 66, 254-272.

CHESHIRE, P.; SHEPPARD, S. (1998). "Estimating the Demand for Housing, Land and Neighborhood Characteristics". Oxford Bulletin of Economics and Statistics, 60 (3): 357-382.

DUBIN, R. A. (1992). "Spatial Autocorrelation and Neighborhood Quality”. Regional Science and Urban Economics, 22, 433-452. 
ESPEY, M. e LOPEZ, H. (2000). "The Impact of Airport Noise and Proximity on Residential Property Values”. Growth and Change. v. 31 (Summer 2000): 408419.

FIPE (1999). Pesquisa de Orçamentos Familiares. São Paulo, Universidade de São Paulo

FUJITA, M. e OGAWA, H. (1982). "Multiple Equilibria and Structural Transition of Non-Monocentric Urban Configuration". Regional Science and Urban Economics, 12, 161-196.

HALVORSEN, R. e POLLAKOWSKI, H. O. (1981). "Choice of Functional Form for Hedonic Price Equations". Journal of Urban Economics, 10:37-49.

HARMAN, H. (1967). Modern Factor Analysis. Chicago: The University of Chicago Press.

KAIN, J. F. e QUINLEY, J. M. (1970). "Measuring the Value of Housing Quality”. Journal of the American Statistical Association, 65:532-548.

MACEDO, P. B. R. (1998). "Hedonic Price Models with Spatial Effects: an application to the house market of Belo Horizonte, Brazil". Revista Brasileira de Economia, 52(1), 63-81.

MILLS, E. (1972). Studies in the Structure of the Urban Economy. Baltimore: Johns Hopkins University Press.

OLIVEIRA, R. G. de (1997). Dois Estudos sobre a Poluição do Ar na Cidade de São Paulo. São Paulo: Universidade de São Paulo.

PLAUT, P. O.; PLAUT, S. E. (1998). “Endogenous Identification of Multiple Housing Price Centers in Metropolitan Areas". Journal of Housing Economics, 7, 193217.

ROSEN, S. (1974). "Hedonic Price and Implicit Markets: Product Differentiation in Pure Competition”. Journal of Political Economics, 82: 34-55.

SHEPPARD, S. (1999). "Hedonic Analysis of Housing Markets". Handbook of Regional and Urban Economics. v. 3, 1.595-1.635.

WHEATON, W.C. (1974). "Comparative Static Analysis of Urban spatial Structure”. Journal of Economic Theory, 9:223-237. 


\section{Apêndice}

Tabela A1: Regressão Linear sobre Variáveis de Controle

\begin{tabular}{lrccccccc}
\hline & \multicolumn{2}{c}{ Estruturais } & \multicolumn{2}{c}{ Monocêntrico } & \multicolumn{2}{c}{ Duocêntrico.a } & \multicolumn{2}{c}{ Duocêntrico.b } \\
\hline & coef. & prob. & coef. & prob. & coef. & prob. & coef. & \multicolumn{1}{c}{ prob. } \\
\hline C & 5.4269 & 0.8000 & 110.467 & 0.0000 & 141.730 & 0.0000 & 127.296 & 0.0000 \\
SALA & 98.0056 & 0.0000 & 86.3086 & 0.0000 & 88.1702 & 0.0000 & 89.6973 & 0.0000 \\
GARAG & 35.7380 & 0.0132 & 33.1132 & 0.0136 & 32.5380 & 0.0137 & 33.8935 & 0.0107 \\
DORM_AG & 85.1302 & 0.0000 & 79.5253 & 0.0000 & 75.1090 & 0.0000 & 75.5536 & 0.0000 \\
COZ_AG & 31.9309 & 0.0086 & 34.6248 & 0.0022 & 32.3206 & 0.0037 & 31.7707 & 0.0046 \\
BAN_AG & 88.8489 & 0.0000 & 86.1656 & 0.0000 & 85.5305 & 0.0000 & 85.3293 & 0.0000 \\
OUT_DEP & -37.1034 & 0.0012 & -18.2659 & 0.0915 & -16.0606 & 0.1314 & -18.3653 & 0.0859 \\
DIST_SE & & & -8.4636 & 0.0000 & -4.3816 & 0.0012 & & \\
DIST_BER & & & & & -4.9783 & 0.0000 & & \\
DIST_CBD & & & & & & & -9.3011 & 0.0000 \\
DUM_SE & & & & & & & -14.7637 & 0.2467 \\
\hline $\mathrm{R}^{2}$ adj & 0.5786 & 0.6353 & & 0.6477 & & 0.6437 & \\
\hline \hline
\end{tabular}

Tabela A2:

Correlograma: Renda X Variáveis Ambientais

\begin{tabular}{lrr}
\hline & RENDA & \multicolumn{1}{c}{ Sig. } \\
\hline DIST_MET & -0.468 & 0.000 \\
DIST_TRE & -0.010 & 0.822 \\
TCONST_C & 0.428 & 0.000 \\
TCONST_I & -0.089 & 0.046 \\
PI_99 & -0.120 & 0.008 \\
COEF_ARB & 0.294 & 0.000 \\
CRIME & -0.689 & 0.000 \\
POP_FAV & -0.357 & 0.000 \\
Z_ER & 0.084 & 0.061 \\
Z_RM & 0.291 & 0.000 \\
Z_M & 0.346 & 0.000 \\
Z_I & 0.003 & 0.950 \\
Z_E & -0.070 & 0.117 \\
\hline \hline
\end{tabular}


Tabela A3: Variância Explicada pelos Fatores

\begin{tabular}{crr}
\hline Fator & \multicolumn{1}{c}{$\begin{array}{c}\text { Variância } \\
\text { Explicada (\%) }\end{array}$} & $\begin{array}{c}\text { Variância } \\
\text { Acumulada (\%) }\end{array}$ \\
\hline 1 & 30.249 & 30.249 \\
2 & 16.346 & 46.595 \\
3 & 14.490 & 61.085 \\
4 & 12.908 & 73.993 \\
5 & 11.627 & 85.620 \\
6 & 9.489 & 95.109 \\
7 & 4.891 & 100 \\
\hline \hline
\end{tabular}

Tabela A4:

Partículas Inaláveis por Estação Medidora - São Paulo

\begin{tabular}{clr}
\hline Cod_Est & \multicolumn{1}{c}{ Estação } & PART_IN \\
\hline 1 & D. Pedro II & 54 \\
2 & Santana & 55 \\
3 & Moóca & 53 \\
4 & Cambuci & 45 \\
5 & Ibirapuera & 43 \\
6 & Nossa Senhora do Ó & 46 \\
7 & S Caetano & 44 \\
8 & Congonhas & 48 \\
9 & Lapa & 40 \\
10 & Cerqueira César & 44 \\
11 & Penha & 40 \\
12 & Centro & 45 \\
13 & Garulhos & 64 \\
14 & St Andre - Centro & 40 \\
15 & Diadema & 41 \\
16 & Santo Amaro & 44 \\
17 & Osasco & 55 \\
18 & S André - Capuava & 55 \\
19 & S Bernardo do Campo & 52 \\
20 & Taboa da Serra & 53 \\
21 & S Miguel & 52 \\
22 & Maua & 41 \\
27 & Pinheiros & 41 \\
\hline \hline Fon & CETESB (2002). & \\
\hline
\end{tabular}

Fonte: CETESB (2002). 
Tabela A5: Variáveis Ambientais por Distrito - São Paulo

\begin{tabular}{|c|c|c|c|c|c|c|}
\hline cod_dist & distritos & tconst_com & tconst_ind & coef_arb & crime & pop_fav \\
\hline 1 & Água Rasa & 14.18 & 8.94 & 0.59 & 21.42 & 0.00 \\
\hline 2 & Alto de Pinheiros & 10.29 & 0.62 & 21.93 & 16.49 & 0.69 \\
\hline 3 & Anhanguera & 8.39 & 2.49 & 4.15 & 36.01 & 0.00 \\
\hline 4 & Aricanduva & 14.29 & 8.97 & 2.08 & 46.89 & 5.38 \\
\hline 5 & Artur Alvim & 14.27 & 2.45 & 2.08 & 66.83 & 4.11 \\
\hline 6 & Barra Funda & 20.67 & 17.05 & 6.17 & 43.46 & 4.85 \\
\hline 7 & Bela Vista & 36.01 & 0.21 & 0.52 & 25.49 & 0.00 \\
\hline 8 & Belém & 26.13 & 22.55 & 0.59 & 32.10 & 2.68 \\
\hline 9 & Bom Retiro & 40.91 & 10.07 & 0.52 & 48.69 & 1.42 \\
\hline 10 & Brás & 46.21 & 15.36 & 0.52 & 93.47 & 0.00 \\
\hline 11 & Brasilândia & 11.00 & 1.97 & 3.78 & 92.31 & 16.60 \\
\hline 12 & Butantã & 31.94 & 1.13 & 13.02 & 30.74 & 0.26 \\
\hline 13 & Cachoeirinha & 12.60 & 1.51 & 3.78 & 77.75 & 17.42 \\
\hline 14 & Cambuci & 23.42 & 18.52 & 0.52 & 29.41 & 0.00 \\
\hline 15 & Campo Belo & 15.05 & 4.06 & 13.33 & 26.88 & 6.86 \\
\hline 16 & Campo Grande & 15.33 & 22.53 & 13.33 & 44.41 & 2.18 \\
\hline 17 & Campo Limpo & 11.64 & 2.90 & 11.97 & 93.83 & 13.65 \\
\hline 18 & Cangaíba & 11.94 & 4.04 & 2.08 & 47.95 & 6.38 \\
\hline 19 & Capão Redondo & 11.40 & 2.05 & 11.97 & 93.02 & 18.65 \\
\hline 20 & Carrão & 17.61 & 9.97 & 2.08 & 18.19 & 0.00 \\
\hline 21 & Casa Verde & 16.62 & 4.60 & 3.78 & 38.15 & 0.00 \\
\hline 22 & Cidade Ademar & 11.46 & 7.03 & 13.33 & 106.06 & 16.22 \\
\hline 23 & Cidade Dutra & 11.53 & 4.03 & 11.37 & 80.64 & 20.44 \\
\hline 24 & Cidade Lider & 14.35 & 2.62 & 3.62 & 49.02 & 3.55 \\
\hline 25 & Cidade Tiradentes & 8.10 & 5.71 & 3.62 & 88.88 & 0.62 \\
\hline 26 & Consolação & 33.05 & 0.07 & 0.52 & 19.60 & 0.00 \\
\hline 27 & Cursino & 18.41 & 3.66 & 10.19 & 50.09 & 1.87 \\
\hline 28 & Ermelino Matarazzo & 11.18 & 8.79 & 2.08 & 48.40 & 4.76 \\
\hline 29 & Freguesia do Ó & 14.44 & 8.25 & 3.78 & 41.78 & 2.80 \\
\hline 30 & Grajaú & 11.53 & 4.04 & 11.37 & 95.62 & 19.50 \\
\hline 31 & Guaianazes & 10.74 & 1.74 & 3.62 & 72.62 & 0.19 \\
\hline 32 & Moema & 17.55 & 0.40 & 4.53 & 4.11 & 0.00 \\
\hline 33 & Iguatemi & 10.11 & 5.05 & 2.33 & 100.11 & 3.26 \\
\hline 34 & Ipiranga & 19.65 & 14.16 & 10.19 & 53.55 & 6.13 \\
\hline 35 & Itaim Bibi & 35.05 & 1.58 & 21.93 & 19.18 & 0.38 \\
\hline 36 & Itaim Paulista & 14.26 & 2.93 & 3.62 & 76.82 & 4.29 \\
\hline 37 & Itaquera & 14.62 & 2.68 & 3.62 & 64.47 & 3.23 \\
\hline 38 & Jabaquara & 15.56 & 6.16 & 13.33 & 57.05 & 10.17 \\
\hline 39 & Jaçanã & 13.53 & 4.53 & 8.52 & 76.39 & 2.64 \\
\hline 40 & Jaguara & 11.61 & 14.17 & 6.17 & 53.02 & 1.97 \\
\hline 41 & Jaguaré & 13.92 & 26.42 & 6.17 & 61.95 & 26.73 \\
\hline 42 & Jaraguá & 11.75 & 9.18 & 7.51 & 48.56 & 6.21 \\
\hline 43 & Jardim Angela & 13.94 & 3.45 & 11.97 & 116.23 & 15.75 \\
\hline
\end{tabular}




\begin{tabular}{|c|c|c|c|c|c|c|}
\hline cod_dist & distritos & tconst_com & tconst_ind & coef_arb & crime & pop_fav \\
\hline$\overline{44}$ & Jardim Helena & 9.49 & 11.49 & 3.62 & 61.79 & 12.70 \\
\hline 45 & Jardim Paulista & 23.54 & 0.15 & 21.93 & 8.22 & 0.00 \\
\hline 46 & Jardim São Luis & 14.10 & 3.59 & 11.97 & 103.75 & 21.01 \\
\hline 47 & J. José Bonifácio & 9.60 & 2.82 & 3.62 & 60.98 & 0.00 \\
\hline 48 & Lapa & 24.37 & 14.85 & 6.17 & 28.06 & 0.00 \\
\hline 49 & Liberdade & 26.49 & 3.43 & 0.52 & 18.04 & 0.00 \\
\hline 50 & Limão & 16.94 & 12.99 & 3.78 & 48.88 & 5.24 \\
\hline 51 & Mandaqui & 11.31 & 1.68 & 8.52 & 30.77 & 0.42 \\
\hline 52 & Marsilac & 7.85 & 1.53 & 11.37 & 50.70 & 0.00 \\
\hline 53 & Mooca & 17.61 & 14.78 & 0.59 & 26.11 & 0.00 \\
\hline 54 & Morumbi & 14.38 & 0.71 & 13.02 & 81.71 & 14.30 \\
\hline 55 & Parelheiros & 7.85 & 1.53 & 11.37 & 91.52 & 6.66 \\
\hline 56 & Pari & 41.98 & 11.95 & 0.52 & 54.16 & 0.00 \\
\hline 57 & Parque do Carmo & 10.08 & 8.36 & 3.62 & 72.70 & 4.88 \\
\hline 58 & Pedreira & 10.20 & 5.34 & 13.33 & 82.09 & 26.53 \\
\hline 59 & Penha & 20.47 & 4.18 & 2.08 & 37.71 & 1.48 \\
\hline 60 & Perdizes & 17.22 & 1.00 & 6.17 & 14.73 & 0.00 \\
\hline 61 & Perus & 9.19 & 9.79 & 4.15 & 53.79 & 4.34 \\
\hline 62 & Pinheiros & 33.10 & 0.50 & 21.93 & 19.49 & 0.00 \\
\hline 63 & Pirituba & 13.20 & 5.23 & 7.51 & 49.23 & 4.83 \\
\hline 64 & Ponte Rasa & 13.48 & 2.92 & 2.08 & 45.45 & 3.28 \\
\hline 65 & Raposo Tavares & 11.96 & 15.76 & 13.02 & 50.74 & 10.23 \\
\hline 66 & República & 68.17 & 0.08 & 0.52 & 57.11 & 0.00 \\
\hline 67 & Rio Pequeno & 10.80 & 2.43 & 13.02 & 74.51 & 19.67 \\
\hline 68 & Sacomã & 10.01 & 13.72 & 10.19 & 67.45 & 20.34 \\
\hline 69 & Santa Cecilia & 21.60 & 2.41 & 0.52 & 13.75 & 0.00 \\
\hline 70 & Santana & 16.33 & 2.79 & 8.52 & 19.27 & 0.89 \\
\hline 71 & Santo Amaro & 29.23 & 12.82 & 13.33 & 42.02 & 0.00 \\
\hline 72 & São Lucas & 13.68 & 6.84 & 1.19 & 47.24 & 1.35 \\
\hline 73 & São Mateus & 11.55 & 5.87 & 2.33 & 62.35 & 12.44 \\
\hline 74 & São Miguel & 20.87 & 2.22 & 3.62 & 63.96 & 5.61 \\
\hline 75 & São Rafael & 11.04 & 4.78 & 2.33 & 96.16 & 6.78 \\
\hline 76 & Sapopemba & 11.32 & 2.44 & 1.19 & 77.68 & 9.31 \\
\hline 77 & Saúde & 17.71 & 2.03 & 4.53 & 19.16 & 1.12 \\
\hline 78 & Sé & 65.89 & 0.59 & 0.52 & 107.62 & 0.00 \\
\hline 79 & Socorro & 12.42 & 24.48 & 11.37 & 59.70 & 1.31 \\
\hline 80 & Tatuapé & 18.60 & 10.75 & 0.59 & 28.99 & 0.00 \\
\hline 81 & Tremembé & 10.58 & 2.16 & 8.52 & 57.80 & 2.19 \\
\hline 82 & Tucuruvi & 13.53 & 2.80 & 8.52 & 38.44 & 0.00 \\
\hline 83 & Vila Andrade & 9.80 & 2.37 & 11.97 & 50.07 & 45.69 \\
\hline 84 & Vila Curuçá & 11.84 & 1.56 & 3.62 & 59.08 & 6.70 \\
\hline 85 & Vila Formosa & 15.24 & 5.35 & 2.08 & 26.91 & 0.88 \\
\hline 86 & Vila Guilherme & 25.88 & 7.94 & 1.83 & 45.01 & 0.00 \\
\hline 87 & Vila Jacuí & 15.01 & 2.90 & 2.08 & 65.67 & 10.52 \\
\hline 88 & Vila Leopoldina & 16.28 & 21.66 & 6.17 & 49.61 & 11.24 \\
\hline 89 & Vila Maria & 24.01 & 12.04 & 1.83 & 64.48 & 7.60 \\
\hline
\end{tabular}




\begin{tabular}{clrrrrr}
\hline cod_dist & distritos & tconst_com tconst_ind & coef_arb & crime & pop_fav \\
\hline 90 & Vila Mariana & 19.62 & 1.17 & 4.53 & 11.55 & 0.87 \\
91 & Vila Matilde & 14.50 & 3.62 & 2.08 & 28.01 & 0.00 \\
92 & Vila Medeiros & 12.56 & 6.77 & 1.83 & 55.69 & 2.49 \\
93 & Vila Prudente & 13.92 & 11.23 & 1.19 & 47.84 & 7.43 \\
94 & Vila Sônia & 9.07 & 2.25 & 13.02 & 47.51 & 14.93 \\
95 & São Domingos & 11.61 & 14.17 & 7.51 & 42.12 & 8.55 \\
96 & Lajeado & 11.42 & 1.34 & 3.62 & 64.45 & 3.84 \\
\hline \hline
\end{tabular}

Fonte: SEADE (2000).

Tabela A6: Agregação das Zonas Urbanas

\begin{tabular}{|l|l|c|}
\hline \multicolumn{1}{|c|}{$\begin{array}{c}\text { Zonas } \\
\text { Agregadas }\end{array}$} & \multicolumn{1}{|c|}{ Descrição } & $\begin{array}{c}\text { Zonas } \\
\text { Originais }\end{array}$ \\
\hline Z_ER & zona estritamente residencial & Z1 e Z15 \\
\hline Z_RB & zona residencial de densidade demográfica baixa & $\begin{array}{c}\text { Z2, Z9, Z11 e } \\
\text { Z14 }\end{array}$ \\
\hline Z_RM & zona residencial de densidade demográfica média & $\begin{array}{c}\text { Z3, Z10, Z12, } \\
\text { Z13, Z17 e Z18 }\end{array}$ \\
\hline Z_M & zona mista & Z4 e Z5 \\
\hline Z_I & zona industrial & Z6 e Z7 \\
\hline Z_E & zonas especiais & Z8 e Z16 \\
\hline \hline
\end{tabular}




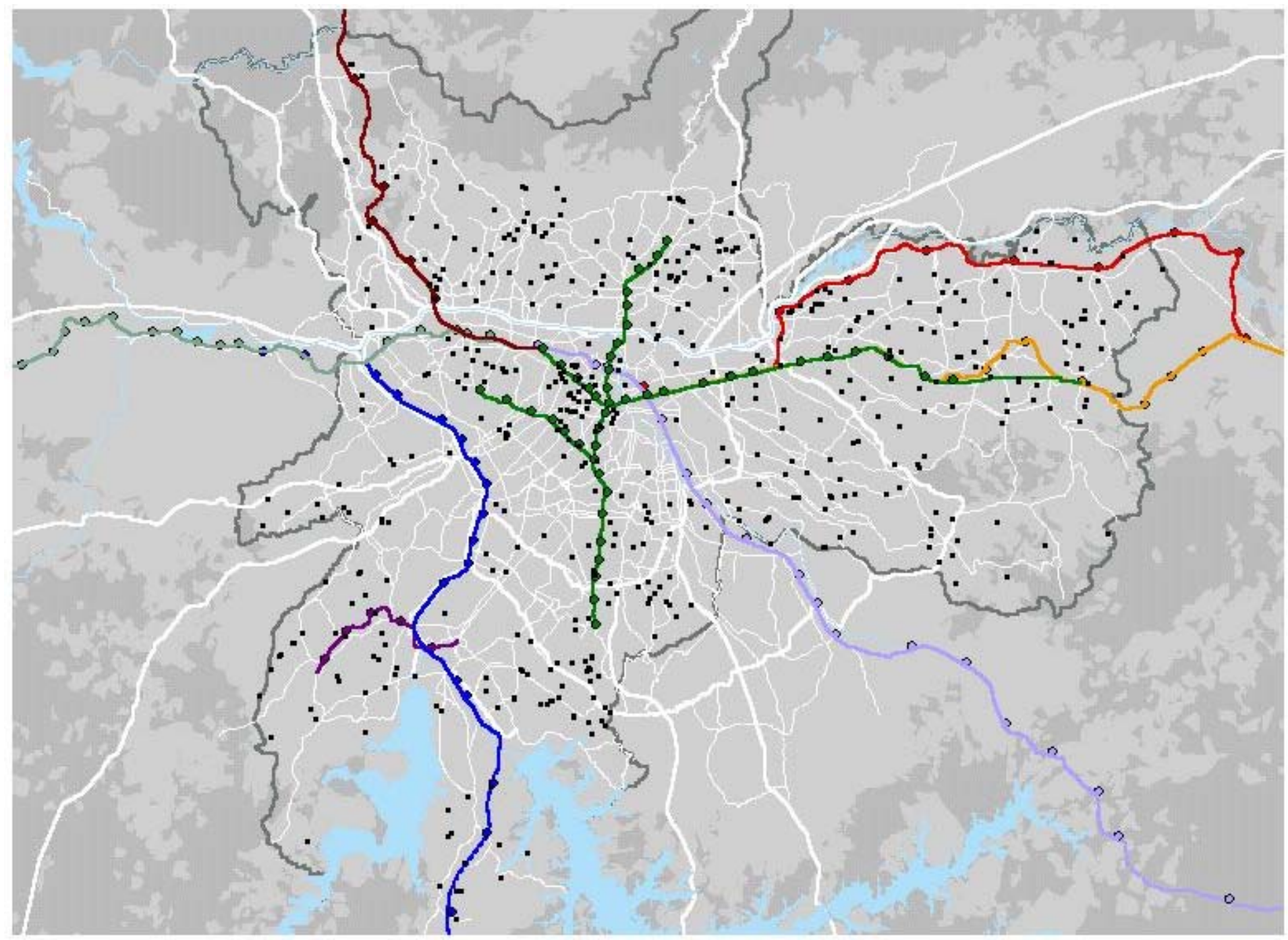

Mapa A1:

Sistema

Ferroviário -

São Paulo

Domicílios

Nimente

Ferovia Lintia

A Ferrovia Linha

Nerowa thang

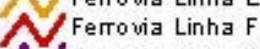

Ferrovia Linha G

Rios

Represas
Awenidas

V Vário Regiona

$\square$ Limite Municipal

Mancha Urbana

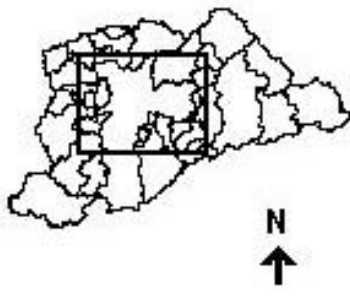

\section{$\stackrel{N}{\uparrow}$}

Kilometers

ONTES:

Eu barado a pa rir de dadas:

LUWW 2002:
FIPE 1999 


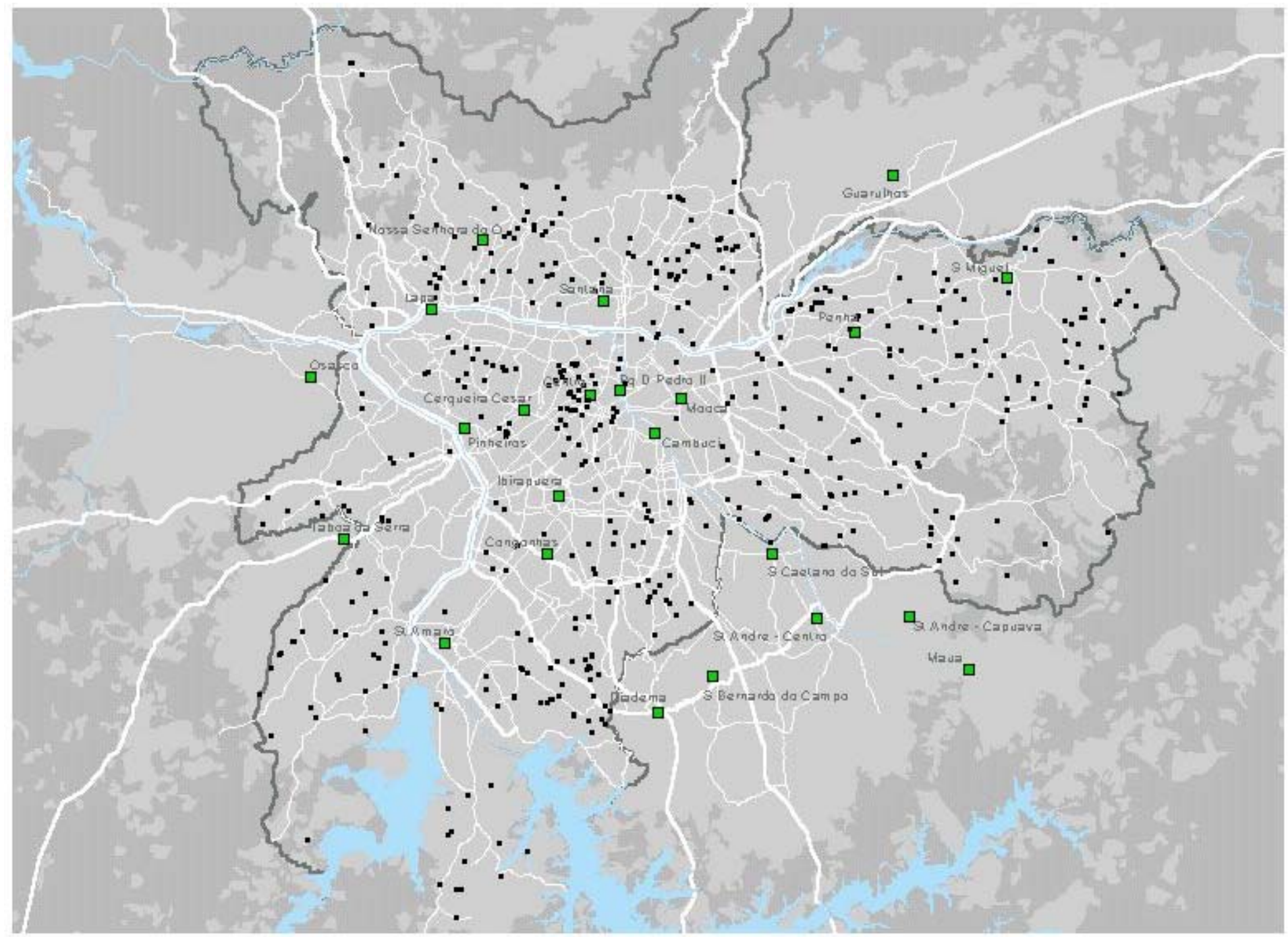

Mapa A2:

Estações

Medidoras de

Poluição -

São Paulo

- Domicílios

Estaçóes Rios

Represas

Aven id as

V. Viário Regional

Limite do Municipa

Mancha urbana

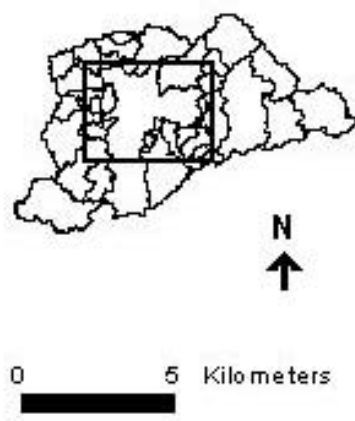

FONTES:

Eu barada a pa hir de dadas:

CUT

CIPE 1999 . 

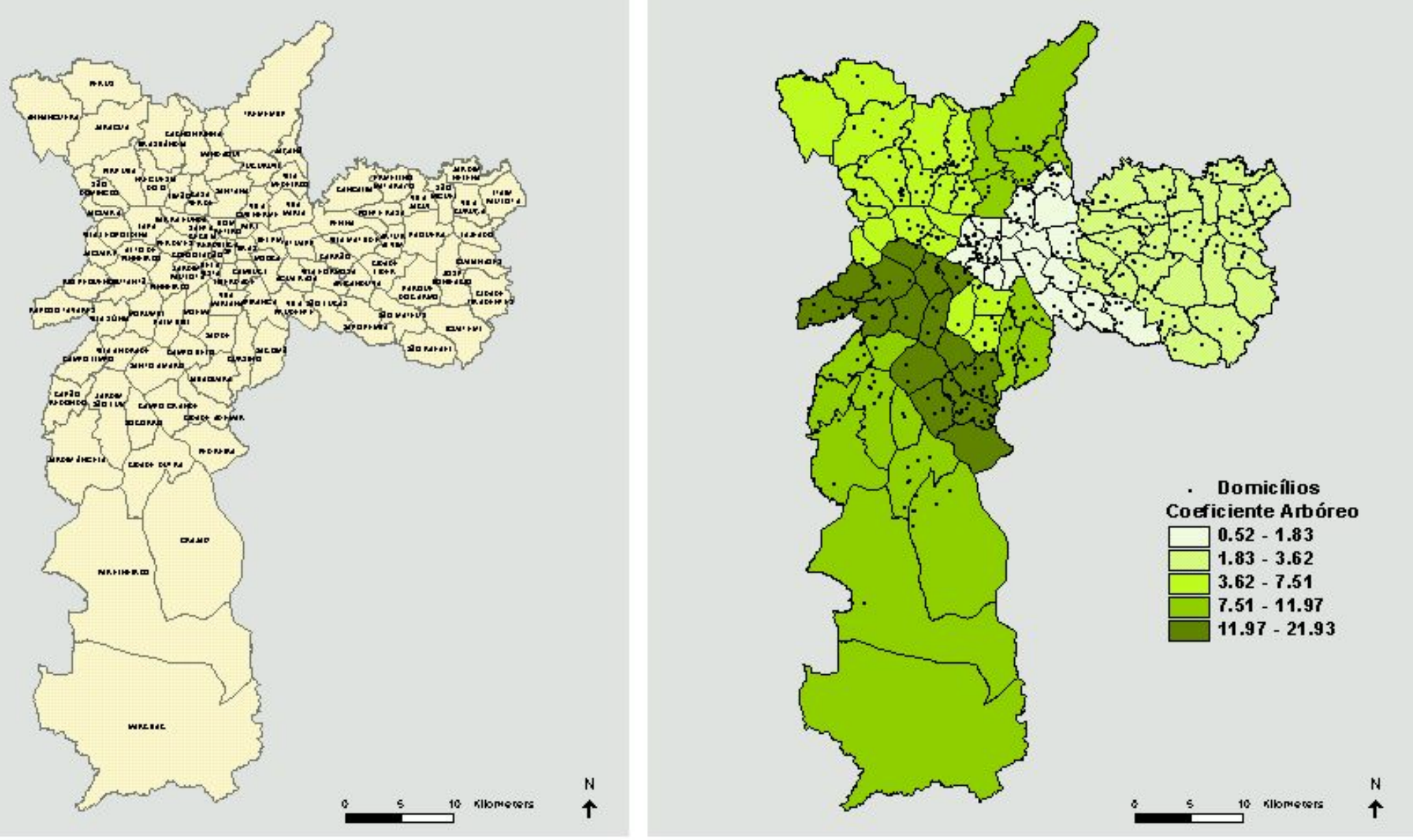
Mapa A4: Características Distritais -

FONTES:

Taxa de Construção Comercial e Industrial - São Paulo

Eu barada a pa hir de dadas: ULWE 2002 : SEMDE 2000
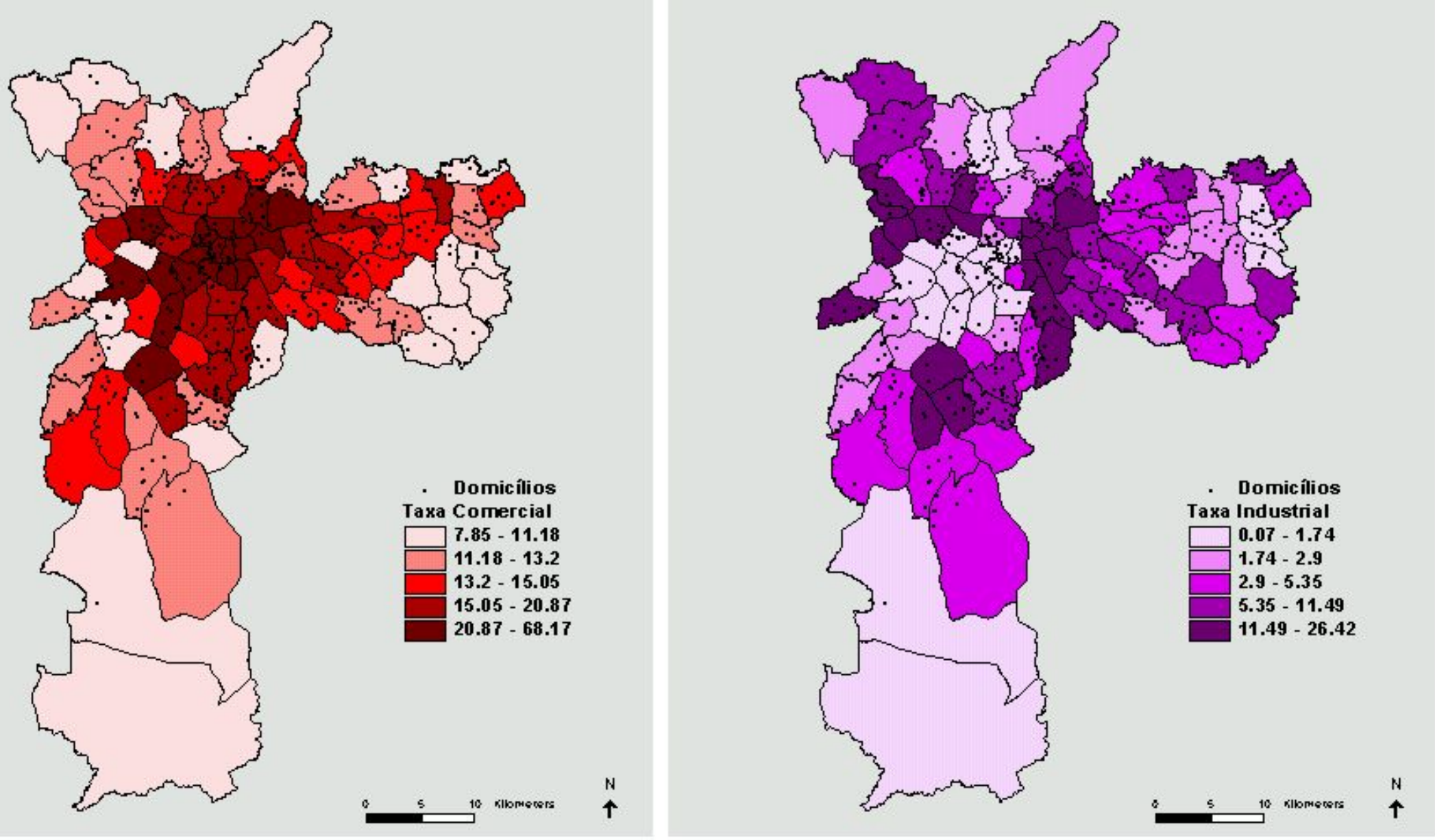
Mapa A5: Características Distritais -

Índice de Criminalidade e População Favelada - São Paulo

FONTES:

Eu barada a pa mirde dadas:

LU LIE 2002: S EMDE 2000
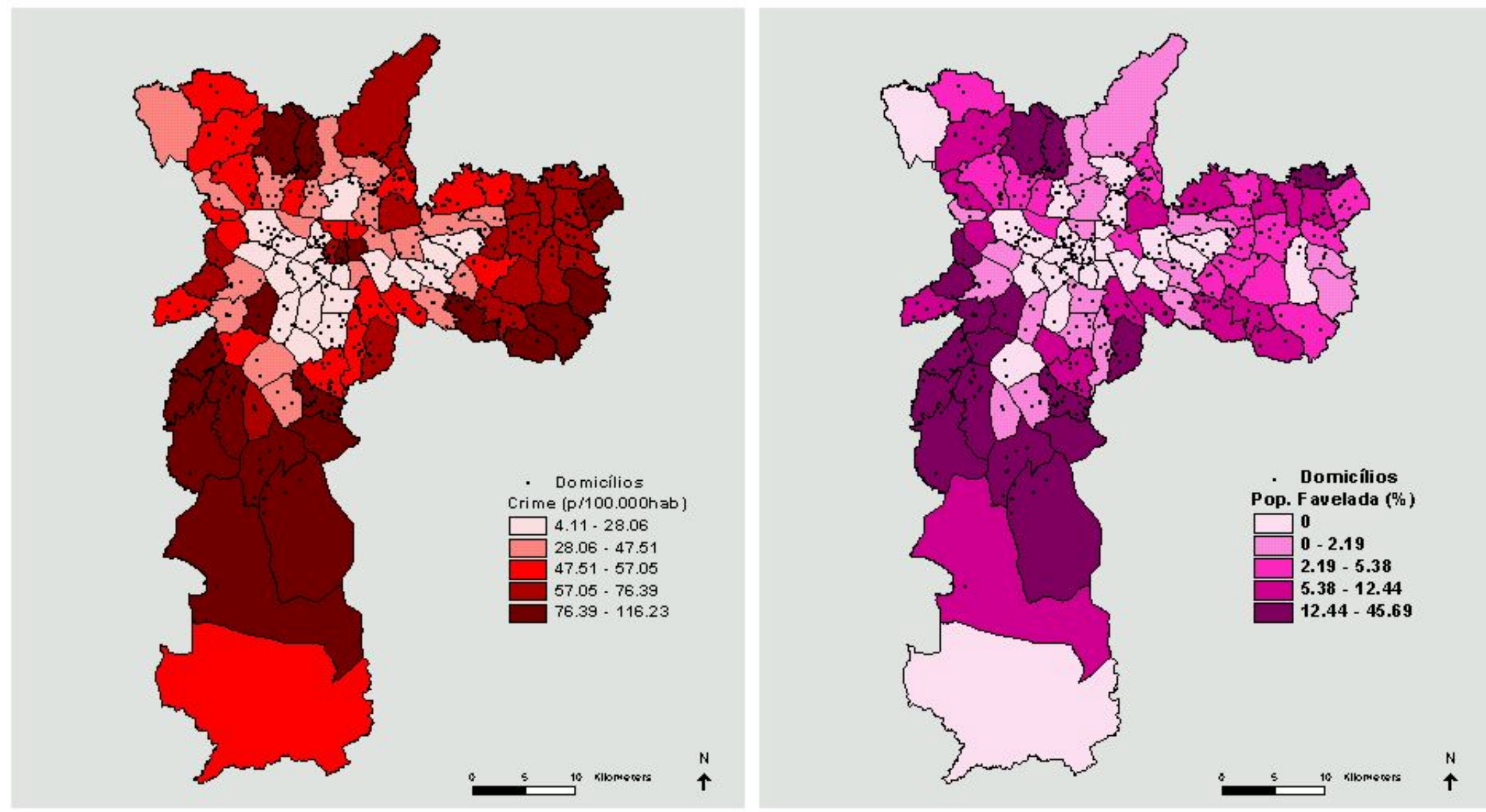